\title{
Treatment of bipolar disorders during pregnancy: maternal and fetal safety and challenges
}

\author{
This article was published in the following Dove Press journal: \\ Drug, Healthcare and Patient Safety \\ 24 December 2014 \\ Number of times this article has been viewed
}

\author{
Richard A Epstein' \\ Katherine M Moore ${ }^{2}$ \\ William $\vee$ Bobo $^{2}$ \\ 'Department of Psychiatry, Vanderbilt \\ University School of Medicine, \\ Nashville, TN, ${ }^{2}$ Department of \\ Psychiatry and Psychology, Mayo \\ Clinic, Rochester, MN, USA
}

\begin{abstract}
Treating pregnant women with bipolar disorder is among the most challenging clinical endeavors. Patients and clinicians are faced with difficult choices at every turn, and no approach is without risk. Stopping effective pharmacotherapy during pregnancy exposes the patient and her baby to potential harms related to bipolar relapses and residual mood symptomrelated dysfunction. Continuing effective pharmacotherapy during pregnancy may prevent these occurrences for many; however, some of the most effective pharmacotherapies (such as valproate) have been associated with the occurrence of congenital malformations or other adverse neonatal effects in offspring. Very little is known about the reproductive safety profile and clinical effectiveness of atypical antipsychotic drugs when used to treat bipolar disorder during pregnancy. In this paper, we provide a clinically focused review of the available information on potential maternal and fetal risks of untreated or undertreated maternal bipolar disorder during pregnancy, the effectiveness of interventions for bipolar disorder management during pregnancy, and potential obstetric, fetal, and neonatal risks associated with core foundational pharmacotherapies for bipolar disorder.
\end{abstract}

Keywords: bipolar disorder, pregnancy, anticonvulsants, antiepileptics, antipsychotics, safety

\section{Introduction}

Bipolar disorders, including bipolar I disorder, bipolar II disorder, and bipolar disorder not otherwise specified, are serious, chronic psychiatric illnesses characterized by alternating episodes of mania or hypomania and major depression, or mixtures of manic and depressive features. ${ }^{1}$ They represent a spectrum of illnesses characterized by frequent relapses, symptom recurrences, and persisting residual symptomatology. ${ }^{2}$ Bipolar disorders have major adverse clinical, social, and economic effects that often interfere with the patient's ability to work and function normally in other instrumental life roles and in social relationships. ${ }^{3-7}$ The annual incidence of bipolar disorders ranges from three to ten cases per 100,000 population, ${ }^{8}$ with an estimated lifetime prevalence of $3 \%-7 \% .^{9-11}$

Although bipolar disorders cannot be cured, they can generally be managed in both acute exacerbations and in maintenance treatment with appropriate pharmacotherapy, including mood stabilizers, selected antipsychotic medications, or combinations of these. ${ }^{12}$ The overarching goal of treatment is to achieve or maintain a euthymic mood state and maximize daily functioning in all important life domains. ${ }^{13}$ However, the longitudinal course of bipolar disorders is marked by frequent relapses, particularly when effective pharmacotherapy is discontinued. ${ }^{14-16}$ As such, long-term treatment with mood-stabilizing medications is typically required. ${ }^{17}$
Correspondence: Richard A Epstein Department of Psychiatry, Vanderbilt University School of Medicine, Village at Vanderbilt Suite 2200, I500 2 Ist Avenue South, Nashville, TN 37212, USA

$\mathrm{Tel}+\mathrm{I} 6153434497$

Fax + I 6I5 3221578

Email richard.a.epstein@vanderbilt.edu 
The incidence of bipolar disorders in women peaks from 12 to 30 years of age, ${ }^{14,18,19} \mathrm{eg}$, during the primary reproductive years, raising the possibility of considerable bipolar illness burden during pregnancy and the postpartum period. The period prevalence of bipolar disorders does not appear to differ significantly between pregnant and nonpregnant women, ${ }^{20,21}$ although some have reported lower prevalence rates of bipolar and other mood disorders during pregnancy than outside of pregnancy. ${ }^{20}$ Still, episodes of mania or depression are thought to occur in an estimated 25\%-30\% of women with bipolar disorder during pregnancy. ${ }^{22,23}$ Even higher rates of illness recurrence during pregnancy have been reported after stopping mood stabilizers (see 'Maintenancephase treatment' on page 4). As such, there is no clear evidence that pregnancy itself protects affected women from bipolar mood episodes.

The treatment of bipolar disorders during pregnancy presents numerous clinical challenges. As discussed in greater detail here, many primary mood stabilizers are associated with increased risk of congenital malformations; however, stopping treatment during pregnancy may increase the risk of bipolar mood-episode relapses. In the last 15 years, there has been increasing antepartum use of atypical antipsychotic drugs, many of which could be viable alternatives to mood stabilizers. ${ }^{24,25}$ However, relatively little is known about the reproductive safety of these agents. To make informed choices about managing bipolar disorder during pregnancy, clinicians, patients, and their support systems must weigh the available data addressing the effectiveness and safety of treatments in pregnant patients, and the potential risks of bipolar relapses if treatment is stopped, taking into account each patient's tolerance of risk related to both the underlying illness and available interventions. We provide a clinically focused review of the available information on the effectiveness and safety of pharmacotherapies for treating bipolar disorder during pregnancy, and the potential maternal and fetal risks of untreated bipolar disorder.

\section{Materials and methods}

This review highlights selected clinical and epidemiological studies identified via a Medline/PubMed search of the published literature on the benefits and harms (congenital malformations, adverse neonatal events, obstetrical complications, and adverse effects on neurodevelopment in offspring) of mood stabilizer and antipsychotic drug use during pregnancy (1966-2013). Relevant studies were identified using combinations of terms identifying medication exposures (mood stabilizers, lithium, anticonvulsants, antiepileptic drugs, valproic acid, valproate, divalproex, carbamazepine, lamotrigine, antipsychotic drugs, haloperidol, chlorpromazine, atypical antipsychotic drugs, clozapine, risperidone, olanzapine, quetiapine, ziprasidone, aripiprazole, paliperidone, lurasidone, asenapine, and iloperidone) and outcomes of interest (pregnancy outcome, birth outcome, congenital malformations, birth defects, cardiac/heart defects, Ebstein's anomaly, neural tube defects, oral/facial clefts, birth weight, head circumference, neonatal complications, neonatal toxicity, weight gain, gestational diabetes, neurobehavioral outcomes, and mental retardation). Antidepressants and benzodiazepines are frequently used to treat patients with bipolar disorders ${ }^{26}$; however, neither are considered to be core foundational treatments for bipolar disorders, and their use for treating patients with bipolar disorder is controversial. ${ }^{27,28}$ As such, these agents are not reviewed in detail here. Additionally, many newer-generation anticonvulsants are sometimes used to treat patients with bipolar spectrum disorders in clinical practice (ie, gabapentin, topiramate, levetiracetam, etc), but have unproven benefit for acute or long-term treatment, and will not be reviewed either. ${ }^{29}$

\section{Clinical impact of maternal bipolar disorder}

A diagnosis of bipolar disorder has been associated with a slight but statistically significant increase in the risk of several pregnancy complications in observational studies. For example, data from an Australian psychiatric case registry (1980-1992) were used to compare rates of pregnancy, delivery, and neonatal complications among 3,174 deliveries to women with diagnosed schizophrenia, major depression, and bipolar disorder (1,301 births among 763 mothers), using a control sample of 3,129 births to women without a psychiatric diagnosis. ${ }^{30} \mathrm{Com}-$ pared to control mothers, mothers with bipolar disorder were at significantly higher risk of experiencing placental abnormalities, antepartum hemorrhages, and toxicities related to alcohol, tobacco, and illicit-substance use. In a large-scale observational study using the Taiwan National Health Insurance Research Database, a diagnosis of bipolar disorder was associated with significantly higher likelihood of low birth weight, preterm birth, and smallness for gestational age delivery compared with absence of a psychiatric diagnosis. ${ }^{31}$ Combined data from three nationwide Swedish registers (including 332,137 women with two or more recorded diagnoses of bipolar disorder) showed that both treated and untreated women with bipolar disorder had higher risk of cesarean delivery and 
preterm delivery, while untreated women had a higher risk of delivering babies with a small head circumference and neonatal hypoglycemia compared with control women with no history of psychiatric illness. ${ }^{32}$ Regardless of treatment status, rates of smoking, overweight, and substance abuse were significantly higher among women with a diagnosis of bipolar disorder compared with control women. In this study, drug exposures to lithium, valproate, carbamazepine, lamotrigine, or antipsychotic drugs were considered in aggregate based on filled prescriptions; the effects of individual agents were not studied.

Previous research has also shown that the offspring of women with bipolar disorder have increased rates of neurocognitive and psychiatric impairment. In a cohort study of 117 offspring (ages 4-18 years) of 88 parents with bipolar disorder (high-risk youth) and 171 offspring of parents without a major affective disorder (control youth), high-risk youth had significantly increased rates of affective, anxiety, and disruptive behavioral disorders, memory and attention disturbances, and impaired social functioning than control youth. ${ }^{33}$ These findings have been confirmed in other cohort studies of young offspring of parents with bipolar disorder. ${ }^{34,35}$

Several studies have identified the postpartum period as being one of high risk for first-onset and recurrent depressive, manic, mixed, and psychotic episodes in women with bipolar disorders..$^{36-40}$ Large increases in rates of psychiatric hospitalization within the first few weeks postpartum have also been observed in cohorts of women with bipolar disorder diagnoses. ${ }^{36,37,41,42}$ Bipolar women have at least a one in four risk of suffering a severe recurrence following delivery, including perhaps an even higher risk if there is a family history of postpartum psychosis or a previous history of a severe postpartum bipolar mood episode. ${ }^{43}$

Finally, uncontrolled or untreated bipolar disorder exposes affected mothers to well-documented behavioral risks that accompany acute manic or depressive relapses. These include increases in impulsive and risky behaviors, unplanned pregnancy, substance use, poor adherence to prenatal care, disruptions in support structures and family functioning, and maternal suicide: a leading cause of perinatal mortality. ${ }^{44-47}$

\section{Effectiveness of treatments for bipolar disorders during pregnancy Pharmacotherapy}

Acute manic/mixed episodes

Few controlled studies address the effectiveness of medication treatment for acute bipolar manic or mixed episodes in pregnant women. Although existing studies typically exclude pregnant women, meta-analyses and randomized controlled trials suggest there to be a large number of effective pharmacotherapeutic treatments for treating acute manic or mixed episodes (Table 1), either as single-agent or combination-therapy regimens. ${ }^{48-55}$ There is no consistent evidence of differential clinical benefit from mood-stabilizing medications (such as lithium or olanzapine) according to sex. ${ }^{56-58}$ As such, results from these trials are often extrapolated to pregnant women with acute manic or mixed episodes, mindful of the available reproductive safety data for each treatment option. For instance, a recently published meta-analysis of 68 randomized trials (16,703 subjects) showed that antipsychotic drugs were significantly more effective than mood stabilizers for treating acute mania, and that haloperidol performed the best on an integrated assessment of antimanic effectiveness (based on improvement in mania rating-scale scores) and rates of any-cause dropout from allocated treatment at 3 weeks. ${ }^{59}$ These results and the better-known reproductive safety profile of haloperidol compared with many other agents for treating acute mania may increase its appeal for acute treatment of mania during pregnancy, notwithstanding other factors (eg, extrapyramidal side effects, tardive dyskinesia with longterm use, lack of bipolar antidepressive efficacy, etc) that may limit its usefulness.

\section{Acute depressive episodes}

Fewer established treatments exist for acute bipolar depression than acute manic or mixed episodes (Table 2). As is the case with acute mania, there is a paucity of controlled evidence for treating acute bipolar depression during pregnancy. Randomized trials of patients with bipolar I or II disorder, depressed phase, have also typically excluded pregnant women from participation. Meta-analyses of randomized trials support the effectiveness of quetiapine, an olanzapine-fluoxetine combination, and lamotrigine, ${ }^{60-64}$ although patients with severe depression appear to be more likely to benefit from lamotrigine than those with milder depression. ${ }^{63}$ Other treatments for acute bipolar depression supported by controlled evidence include lurasidone (with or without concomitant mood stabilizers), lamotrigine combined with lithium, and lithium monotherapy. ${ }^{65-69}$ Although a meta-analysis of four small randomized trials showed higher remission rates with valproic acid than placebo,${ }^{70}$ its established teratogenic potential (see 'Valproic acid: Major congenital malformations' on page 8) severely limits the use of this agent during pregnancy to circumstances in which 
Table I Pharmacotherapeutic options for treating acute manic (or mixed) episodes

\begin{tabular}{|c|c|c|c|}
\hline Drug class/name & Regulatory approvala,b & $\begin{array}{l}\text { Pregnancy-safety } \\
\text { rating (US) }\end{array}$ & Summary of major reproductive safety concerns \\
\hline \multicolumn{4}{|l|}{ Mood stabilizers } \\
\hline Lithium & $\begin{array}{l}\text { Adults }^{\text {mono }} \\
\text { Youth (aged 12+ years) }\end{array}$ & $\mathrm{D}$ & $\begin{array}{l}\text { - Overall MCM rate } 2.8 \% \text { (prospective studies) } \\
\text { - Includes low risk of Ebstein's anomaly (one case per } \\
\text { I,000-2,000 births) } \\
\text { - Reported cases of neonatal adaptation syndrome; risk } \\
\text { may be higher with higher maternal lithium levels } \\
\text { - Reported cases of other neonatal complications }\end{array}$ \\
\hline Valproate & Adults ${ }^{\text {mono,* }}$ & $\mathrm{D}$ & $\begin{array}{l}\text { - Highest MCM rates among all mood stabilizers } \\
(5 \%-11 \% \text {, based on registry study data); risk may be } \\
\text { dose-dependent (maternal daily dose) } \\
\text { - Increased MCM risk when combined with other } \\
\text { anticonvulsants } \\
\text { - Increased risk of adverse neurodevelopmental } \\
\text { outcomes } \\
\text { - Reported cases of neonatal toxicity syndromes }\end{array}$ \\
\hline Carbamazepine & Adults ${ }^{\mathrm{d}, \mathrm{mon} o, *}$ & $\mathrm{D}$ & $\begin{array}{l}\text { - Overall MCM rate } 2 \%-6 \% \text { based on registry study data } \\
\text { - Several adverse neonatal events aside from birth } \\
\text { defects reported }\end{array}$ \\
\hline \multicolumn{4}{|l|}{ Antipsychotics, atypical } \\
\hline Clozapine & - & B & - MCM risk unclear, very few large-scale studies \\
\hline Risperidone & Adults mono,com & C & - Very limited data on reproductive risks associated \\
\hline Olanzapine & Adults ${ }^{\text {mono,com,* }}$ & C & with individual drugs \\
\hline Quetiapine & Adults ${ }^{\text {mono,com, } *}$ & C & - FDA safety warning regarding risk of abnormal muscle \\
\hline Ziprasidone & Adultsmono,* & C & movements and withdrawal symptoms in neonates \\
\hline Aripiprazole & Adultsmono,com,* & C & - Possible risks of excessive weight gain and gestational \\
\hline Asenapine & Adults ${ }^{\text {mono,com,* }}$ & C & diabetes require additional study \\
\hline Antipsychotics, typical & Adults (chlorpromazine only) & C & $\begin{array}{l}\text { - Low risk of MCMs, but this is based on very few } \\
\text { reports } \\
\text { - FDA safety warning regarding risk of abnormal muscle } \\
\text { movements and withdrawal symptoms in neonates }\end{array}$ \\
\hline
\end{tabular}

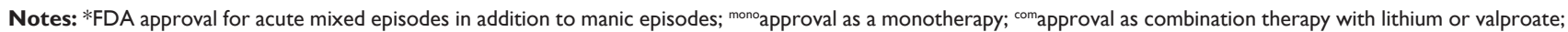
aregulatory approval in the US; bno psychotropic medications (including those used to treat bipolar disorder in any of its phases) are approved for use in the context of pregnancy in the US; information on regulatory approval in the US is for general treatment of bipolar disorder in adults, or in children or youth where specified; 'FDA pregnancy-safety categories are generally defined as: $A=$ adequate, well-controlled human studies fail to show risk to fetus; $B=$ animal studies fail to show risk to fetus, but no adequate, well-controlled studies in humans; $C=$ animal studies show evidence of adverse fetal effects, but no adequate studies in humans - benefits of use in pregnancy may still outweigh risks; $\mathrm{D}$ = investigational or postmarketing studies in humans show evidence of adverse fetal effects, but benefits of use in pregnancy may still outweigh

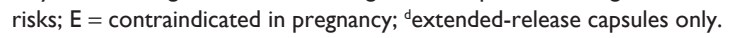

Abbreviations: MCM, major congenital malformation; FDA, US Food and Drug Administration.

valproate is required in order to maintain maternal mood stability.

\section{Maintenance-phase treatment}

A number of bipolar maintenance options are available (Table 3), and there is evidence from controlled observational studies addressing the effectiveness of continuing versus stopping effective bipolar maintenance treatment during pregnancy. In a retrospective study, Viguera et al compared recurrence rates for 42 patients with bipolar I or II disorder during pregnancy or the postpartum period following rapid (over $\leq 14$ days) or gradual (over 15-30 days) discontinuation of lithium maintenance therapy. ${ }^{71}$ Lithium discontinuation commenced within 6 weeks of the estimated date of conception. A cohort of 59 age-matched nonpregnant women with bipolar disorder who also discontinued lithium treatment served as a control group. Recurrence rates following lithium discontinuation did not differ significantly between pregnant women and nonpregnant controls ( $52 \%$ versus $58 \%$ ); however, recurrence rates were lower in both groups during the year prior to medication discontinuation (21\%). A total of nine women continued lithium treatment during pregnancy, none of whom relapsed during 40 weeks of follow-up. Rapid lithium discontinuation was 
Table 2 Pharmacotherapeutic options for treating acute depressive episodes

\begin{tabular}{|c|c|c|c|}
\hline Drug class/name & $\begin{array}{l}\text { Regulatory } \\
\text { approval }{ }^{\mathrm{a}, \mathrm{b}}\end{array}$ & $\begin{array}{l}\text { Pregnancy-safety } \\
\text { rating (US) }\end{array}$ & Summary of major reproductive safety concerns \\
\hline \multicolumn{4}{|l|}{ Mood stabilizers } \\
\hline Lithium & - & $\mathrm{D}$ & $\begin{array}{l}\text { - Overall MCM rate } 2.8 \% \text { (prospective studies) } \\
\text { - Includes low risk of Ebstein's anomaly (one case per I,000-2,000 births) } \\
\text { - Reported cases of neonatal adaptation syndrome; risk may be higher } \\
\text { with higher maternal lithium levels } \\
\text { - Reported cases of other neonatal complications }\end{array}$ \\
\hline Valproate & - & $\mathrm{D}$ & $\begin{array}{l}\text { - Highest MCM rates among all mood stabilizers ( } 5 \%-11 \% \text {, based on } \\
\text { registry study data); risk may be dose-dependent (maternal daily dose) } \\
\text { - Increased MCM risk when combined with other anticonvulsants } \\
\text { - Increased risk of adverse neurodevelopmental outcomes } \\
\text { - Reported cases of neonatal toxicity syndromes }\end{array}$ \\
\hline Carbamazepine & - & $\mathrm{D}$ & $\begin{array}{l}\text { - Overall MCM rate } 2 \%-6 \% \text { based on registry study data } \\
\text { - Several adverse neonatal events aside from birth defects reported }\end{array}$ \\
\hline Lamotrigine & - & C & $\begin{array}{l}\text { - Unclear if lamotrigine increases risk of MCMs above background rates } \\
\text { - Unclear if lamotrigine increases risk of other neonatal adverse events } \\
\text { outside of birth defects } \\
\text { - No evidence of increased risk of adverse neurodevelopmental } \\
\text { outcomes }\end{array}$ \\
\hline \multicolumn{4}{|c|}{ Antipsychotics, atypical } \\
\hline Olanzapine & Adults $^{d}$ & $\mathrm{C}$ & $\begin{array}{l}\text { - MCM risk unclear, very few large-scale studies } \\
\text { - Very limited data on reproductive risks associated with individual drugs } \\
\text { - FDA safety warning regarding risk of abnormal muscle movements and } \\
\text { withdrawal symptoms in neonates } \\
\text { - Possible risks of excessive weight gain and gestational diabetes require } \\
\text { additional study }\end{array}$ \\
\hline Quetiapine & Adults mono & $\mathrm{C}$ & $\begin{array}{l}\text { - MCM risk unclear, very few large-scale studies } \\
\text { - Very limited data on reproductive risks associated with individual drugs } \\
\text { - FDA safety warning regarding risk of abnormal muscle movements and } \\
\text { withdrawal symptoms in neonates } \\
\text { - Possible risks of excessive weight gain and gestational diabetes require } \\
\text { additional study }\end{array}$ \\
\hline Lurasidone & Adultsmono,com & B & $\begin{array}{l}\text { - No evidence of teratogenicity in animals; no reproductive safety data } \\
\text { in humans } \\
\text { - Available only relatively short time for clinical use }\end{array}$ \\
\hline
\end{tabular}

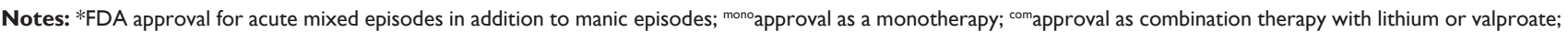
${ }^{a}$ regulatory approval in the US; ${ }^{b}$ no psychotropic medications (including those used to treat bipolar disorder in any of its phases) are approved for use in the context of pregnancy in the US; information on regulatory approval in the US is for general treatment of bipolar disorder in adults, or in children or youth where specified; 'FDA pregnancy-safety categories are generally defined as: $\mathrm{A}=$ adequate, well-controlled human studies fail to show risk to fetus; $\mathrm{B}=$ animal studies fail to show risk to fetus, but no adequate, well-controlled studies in humans; $C=$ animal studies show evidence of adverse fetal effects, but no adequate studies in humans - benefits of use in pregnancy may still outweigh risks; $D=$ investigational or postmarketing studies in humans show evidence of adverse fetal effects, but benefits of use in pregnancy may still outweigh risks; $\mathrm{E}=$ contraindicated in pregnancy; ${ }^{\mathrm{d}}$ combination of olanzapine and fluoxetine for treating acute depressive episodes in adults with bipolar I disorder. Abbreviations: MCMs, major congenital malformations; FDA, US Food and Drug Administration.

associated with higher recurrence rates than gradual tapering (63.3\% versus $37.1 \%)$.

A subsequent prospective cohort study by the same group compared the risk of recurrence in 89 euthymic women with bipolar I or II disorder who continued mood-stabilizer treatment during pregnancy or discontinued mood stabilizers during the time period beginning 6 months before and ending 12 weeks after conception. ${ }^{72}$ The risk of recurrence during pregnancy was $85.5 \%$ for women who discontinued mood stabilizers and $37.0 \%$ for those who continued mood-stabilizer treatment. Median time to recurrence was four times shorter and the proportion of weeks ill during pregnancy was five times greater with mood-stabilizer discontinuation compared with continuation of mood stabilizers. Women who discontinued mood stabilizers spent over $40 \%$ of pregnancy in an episode of illness compared with $8.8 \%$ for those who 
Table 3 Pharmacotherapeutic options for maintenance treatment in patients with bipolar disorder

\begin{tabular}{|c|c|c|c|}
\hline $\begin{array}{l}\text { Drug } \\
\text { class/name }\end{array}$ & $\begin{array}{l}\text { Regulatory } \\
\text { approvala, }^{\mathrm{a}, \mathrm{b}}\end{array}$ & $\begin{array}{l}\text { Pregnancy- } \\
\text { safety rating } \\
\text { (US)c }\end{array}$ & $\begin{array}{l}\text { Summary of major } \\
\text { reproductive } \\
\text { safety concerns }\end{array}$ \\
\hline \multicolumn{4}{|l|}{ Mood stabilizers } \\
\hline Lithium & Adults ${ }^{\mathrm{d}, \mathrm{mono}}$ & $\mathrm{D}$ & See Table I \\
\hline Valproate & - & $\mathrm{D}$ & See Table I \\
\hline Carbamazepine & - & $\mathrm{D}$ & See Table I \\
\hline Lamotrigine & Adults $^{\mathrm{e}}$ & C & See Table 2 \\
\hline \multicolumn{4}{|c|}{ Antipsychotics, atypical } \\
\hline Clozapine & - & B & See Table I \\
\hline Risperidone & Adults & C & See Table I \\
\hline Olanzapine & Adults & C & See Table I \\
\hline Quetiapine & Adults ${ }^{\mathrm{com}}$ & C & See Table I \\
\hline Ziprasidone & Adults ${ }^{\mathrm{com}}$ & C & See Table I \\
\hline Aripiprazole & Adults'sono,com & C & See Table I \\
\hline Asenapine & - & C & See Table I \\
\hline Lurasidone & - & $B$ & See Table 2 \\
\hline $\begin{array}{l}\text { Antipsychotics, } \\
\text { typical }\end{array}$ & $-g$ & C & See Table I \\
\hline \multicolumn{4}{|c|}{ 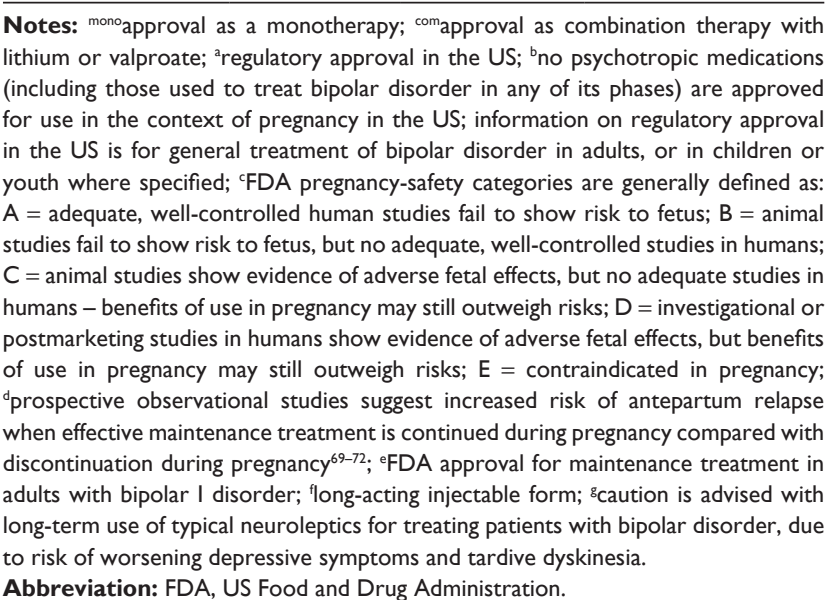 } \\
\hline
\end{tabular}

continued mood stabilizers. Recurrences were predominantly depressed or mixed episodes occurring in the first trimester of pregnancy.

Similar relapse rates were reported in a prospective study of 26 women with bipolar I or II disorder or bipolar disorder not otherwise specified who were clinically euthymic at the time of conception on regimens that included lamotrigine. ${ }^{73}$ A total of 16 patients discontinued mood stabilizers, while ten remained on them during pregnancy. Rates of illness recurrence were $30 \%$ for those who continued lamotrigine and $100 \%$ in those who discontinued all mood stabilizers. Median times to relapse were 7.7 weeks without mood stabilizers, and 32.5 weeks with lamotrigine continuation.

Lower overall rates of relapse during pregnancy were reported by Bergink et al in a naturalistic study of 41 pregnant women with bipolar disorder. ${ }^{74}$ The overall relapse rate during pregnancy was $24.4 \% ; 80 \%$ of women who were treated with lithium pharmacotherapy and $60 \%$ of untreated women remained well during pregnancy.

\section{Postpartum prophylaxis}

Several small studies have investigated the effectiveness of prophylactic use of mood-stabilizing medications to prevent postpartum mood-episode recurrences. For example, in the retrospective study by Viguera et al reviewed earlier, ${ }^{71}$ significantly more pregnant women who had remained euthymic for 40 weeks after discontinuing lithium experienced a postpartum recurrence than did nonpregnant control subjects during the same time period $(70.0 \%$ versus $24.0 \%$ ). Three of the nine women who continued lithium treatment during pregnancy experienced a relapse within 2 weeks of delivery. In another small retrospective study of 27 women with bipolar disorder who were followed during pregnancy and the postpartum period, lower rates of relapse or evidence of affective instability within the first 3 months postpartum were observed among patients who received prophylactic antimanic pharmacotherapy than those who did not receive antimanic medications $(7.1 \%$ versus $61.5 \%){ }^{75}$ Women who received prophylactic pharmacotherapy remained well for a significantly longer period of time than those who did not receive such treatment.

Not all studies have documented such wide differences in postpartum relapse or recurrence rates conditional on receiving prophylactic pharmacotherapy. For example, higher rates of stability in the postpartum period were reported in the naturalistic study by Bergink et al reviewed earlier. ${ }^{74}$ During the postpartum period, 24 of 26 (92.3\%) women who continued medication treatment remained well compared with four of five (80.0\%) of women who declined to continue pharmacotherapy. In addition, a single-blinded, nonrandomized trial of 26 pregnant women with bipolar disorder who received valproate + symptom monitoring or symptom monitoring alone showed no significant between-group differences in the occurrence of mania/hypomania, depression, or mixed states in the postpartum period, although women who received valproic acid + symptom monitoring tended to have lower levels of hypomanic/manic symptoms. ${ }^{76}$

\section{Psychotherapy}

There have been relatively few investigations into the effectiveness of psychotherapy for treating bipolar disorder in pregnant patients, despite the availability of clinically validated approaches and broad recommendations from 
treatment guidelines to integrate pharmacotherapy with targeted psychotherapy when treating patients with bipolar disorder more generally. ${ }^{77}$ Evidence-supported psychotherapies for managing bipolar depression or preventing relapses in stable patients include bipolar-specific cognitive behavioral therapy, family-focused therapy, interpersonal and social rhythm therapy, group psychoeducation, and systematic care management. ${ }^{78-82}$ Evidence-supported psychotherapies are likely to be useful adjuncts to pharmacotherapy in pregnant women with bipolar disorders who struggle with psychosocial stressors that are known to have disruptive effects on illness course and increase risk of relapse, ${ }^{22}$ including negative life events, family discord, other interpersonal difficulties, and disruption of sleep and wake schedules or daily social rhythms. ${ }^{83,84}$

\section{Electroconvulsive therapy}

Electroconvulsive therapy (ECT) is an established shortterm treatment for severe, treatment-resistant unipolar or bipolar major depression, ${ }^{85,86}$ and is sometimes used to effectively treat acute manic states. ${ }^{87}$ Compared with unipolar major depression, the effectiveness of ECT has been less well studied for treating patients with severe or refractory bipolar depression; however, a recent meta-analysis of six heterogeneous studies (totaling 316 patients with bipolar I or II disorder and 790 patients with unipolar major depression) showed similar overall remission rates between bipolar $(53.2 \%)$ and unipolar depressed patients $(50.9 \%) .{ }^{88}$ Even less is understood about the effectiveness of ECT for treating acute bipolar mood episodes in pregnant women, and much of the literature in this specific domain is limited to case reports. ${ }^{89}$ Nevertheless, ECT has been recommended by some as a safe and efficacious treatment of bipolar depressive and manic episodes in pregnant women..$^{90}$

\section{Reproductive safety of pharmacological interventions Lithium}

\section{Major congenital malformations}

Early retrospective studies of the reproductive safety of lithium were derived mainly from the International Register of Lithium Babies, which was initiated in the late 1960s by clinical investigators from North America, Australia, and Europe. Early studies suggested that fetal exposure to lithium was associated with as high as a 400 -fold increase in the risk of congenital heart defects. ${ }^{91-93}$ These included cases of Ebstein's anomaly, a very rare congenital heart defect characterized by apical displacement of the septal and posterior leaflets of the tricuspid valve, variable malformation and/or displacement of the anterior leaflet, and an unfavorable prognosis for cases presenting during infancy. ${ }^{94}$ The final updated summary of data from the registry included a total of 25 congenital malformations occurring among 225 births (11.1\%), 18 of which were cardiovascular malformations, including six cases of Ebstein's anomaly. ${ }^{91}$ However, these data were insufficient to quantify rates of congenital malformation risk with in utero exposure to lithium, because registry data were based on voluntarily contributed cases.

Since then, much of the clinical focus with respect to lithium and the risk of congenital malformations has focused on cases of Ebstein's anomaly in offspring of lithium-treated women. Compared with the International Register of Lithium Babies reports, later studies suggest significant, albeit more moderate, increases in risk. ${ }^{95-97}$ A subsequent quantitative review of two cohort studies (165 exposed pregnancies) and two case-control studies (207 exposed pregnancies) reported that the absolute risk of Ebstein's anomaly with in utero lithium exposure was approximately one case per $1,000-2,000$ births. $^{98}$ It is important to note that this is still roughly ten to 20 times the background rate in the general population of about one per 20,000. ${ }^{99}$

A systematic review of information about the risk of major congenital malformations with in utero exposure to lithium concluded that lithium should not be considered a major human teratogen based on reports published between 1969 and 2005, and that lithium should be administered to pregnant women if indicated. ${ }^{100}$ However, the authors also recommended due caution and supported existing recommendations for performing fetal echocardiography to exclude the possibility of cardiac malformations.

\section{Adverse neonatal events}

Exposure to lithium late in pregnancy has been associated with development of a neonatal adaptation syndrome characterized by hypotonicity, muscle twitching, respiratory and feeding difficulties, cardiac arrhythmias, cyanosis, poor suck, grasp, and Moro reflexes, and lethargy. ${ }^{100-103}$ The syndrome resolves in 1-2 weeks, and usually without further complication; ${ }^{103}$ however, intensive neonatal monitoring and longer hospital stays may be required. ${ }^{103} \mathrm{~A}$ small case series of 32 pregnancies during which lithium was administered throughout delivery documented low Apgar scores, longer hospital stays, and higher rates of central nervous system and neuromuscular complications in infants with higher lithium concentrations at delivery $(>0.64 \mathrm{mEq} / \mathrm{L}) .{ }^{104}$ These findings suggest that the lithium neonatal adaptation 
syndrome may reflect neonatal toxicity, and have prompted recommendations that lithium treatment be suspended 24-48 hours before a scheduled cesarean delivery or at the onset of labor, with reinstatement of lithium following delivery if medically stable. ${ }^{104}$

Other neonatal effects have been associated with maternal lithium use during the second and third trimesters that may reflect complications of lithium use in the neonate, rather than toxicity. These include reversible hypothyroidism, nontoxic goiter, nephrogenic diabetes insipidus, and hypoglycemia. ${ }^{100,104-107}$ The potential effects of maternal lithium use on birth weight were investigated in a prospective cohort study of 148 women with first-trimester lithium use, which consulted teratogen information centers in the US and Canada. ${ }^{95}$ Compared with matched controls, infant birth weight was significantly higher in lithium-exposed infants than control infants $(3,475 \mathrm{~g}$ versus $3,383 \mathrm{~g})$ despite identical gestational ages. However, the absolute differences in birth weight reported in this study were small, and the mean birth weights were within the normal range for both groups. It is also important to note that at least one other study has reported that lithium use during pregnancy was not associated with an increased incidence of large-for-gestational-age deliveries. ${ }^{108}$

\section{Neurodevelopmental outcomes}

Lithium has not been clearly associated with adverse neurodevelopmental or neurobehavioral outcomes in offspring of women who received such treatment during pregnancy. ${ }^{109}$ It is unknown at present whether infants who develop the lithium neonatal adaptation syndrome are at greater risk for long-term neuropsychiatric, neurocognitive, or neurodevelopmental problems.

\section{Valproic acid}

\section{Major congenital malformations}

Numerous studies primarily involving children born to women with epilepsy have documented increased rates of major congenital malformations in general, as well as increased rates of specific birth defects, such as spina bifida and other neural tube defects in particular, associated with in utero exposure to valproate. ${ }^{110-115}$ Rates of major congenital malformations with valproic acid monotherapy are estimated as ranging from $5 \%$ to $11 \%$, based on more recent population-based and specialized epilepsy-registry data. ${ }^{116-119}$ The risk of major congenital malformations with valproate monotherapy has been consistently shown to greatly exceed those of other anticonvulsants, including carbamazepine and lamotrigine. ${ }^{115,117,120-124}$ Further increases in the rate of major congenital malformations (up to 20-fold) associated with valproate have been reported with maternal daily doses exceeding 800-1,000 mg. ${ }^{113,119,123,125,126}$

Rates of specific congenital malformations, as opposed to rates of "any" congenital malformation, have been more difficult to study, because the base rate for individual birth defects is very low. Observational studies have documented an association between maternal valproate use and the risk of a large number of individual major congenital malformations, in addition to neural tube defects, including craniofacial abnormalities, limb defects, and hypospadias. ${ }^{127-131}$ Recent data from the European Surveillance of Congenital Anomalies (EUROCAT) project documented rates of individual major congenital malformations from 19 population-based registries in 14 countries, involving over 3.8 million live births and stillbirths and over 98,000 cases of offspring with major congenital malformations. ${ }^{132}$ Compared with no use of an anticonvulsant drug during the first trimester, first-trimester use of valproate monotherapy was associated with significantly increased risks of spina bifida (odds ratio [OR] 12.7, 95\% confidence interval [CI] 7.7-20.7), craniosynostosis (OR 6.8, 95\% CI 1.8-18.8), cleft palate (OR 5.2, 95\% CI 2.8-9.9), hypospadias (OR 4.8, 95\% CI 2.9-8.1), atrial septal defect (OR 2.5, 95\% CI 1.4-4.4), and polydactyly (OR 2.2, 95\% CI 1.0-4.5). Rates of individual major congenital malformations associated with valproate monotherapy - including neural tube defects, cardiac malformations, oral clefts, and hypospadias - were shown to greatly exceed those of monotherapy with carbamazepine and lamotrigine in a recent review of 21 prospective observational studies. ${ }^{120}$

Major congenital malformation rates associated with valproate exposure have been shown to be higher when combined with other anticonvulsant drugs compared with monotherapy or polytherapy without valproate. ${ }^{116,117,133,134}$ Interestingly, one study actually documented a lower risk of fetal malformations with polytherapy regimens that included valproate compared with monotherapy $(7.3 \%$ versus $17.9 \%){ }^{135}$

\section{Adverse neonatal events}

Maternal use of valproate later in pregnancy has been associated with occurrence of a neonatal toxicity syndrome, the clinical features of which include irritability, feeding problems, abnormalities in muscle tone, liver toxicity, coagulopathies, and hypoglycemia. ${ }^{136-139}$ In a recent prospective, multicenter, cohort study of 329 women with epilepsy who received monotherapy with valproate (62 exposed 
children), carbamazepine, lamotrigine, or phenytoin during pregnancy, rates of small-for-gestational-age delivery were significantly higher in infants exposed to valproate compared with lamotrigine or phenytoin. ${ }^{140}$ Apgar scores were transiently reduced at 1 minute in the group of infants with in utero valproate; however, 5-minute Apgar scores were near normal. Rates of microcephaly were elevated at birth and at 12 months of age (12\%-13\%) for all exposure groups combined, but were only $3 \%$ for all children by age 24 months.

\section{Neurodevelopmental outcomes}

A recent prospective observational multicenter study conducted in the US and UK compared cognitive outcomes of 311 children at 6 years of age born to 305 mothers with epilepsy who received valproate, carbamazepine, lamotrigine, or phenytoin monotherapy during pregnancy. ${ }^{141}$ Analyses were adjusted for maternal intelligence quotient (IQ), anticonvulsant dose, use of periconceptional folate, and gestational age. Mean IQ at age 6 years was significantly lower among valproate-exposed children than those exposed in utero to the other anticonvulsants. Mean IQ scores were significantly lower with higher-dose valproate exposure (as determined by median split) than lower-dose valproate and higher- and lower-dose groups for other anticonvulsants. Interestingly, there were no significant differences in mean IQ scores between children in the lower-dose valproate-exposure group and higher- or lower-dose groups for other anticonvulsants. Mean IQ scores correlated inversely with the maternal daily dose of valproate, while no significant correlation between maternal daily dose of other anticonvulsants and IQ scores was observed. Mean IQs were higher in children exposed to periconceptional folate $(108,95 \%$ CI 106-111) than they were in unexposed children. Most studies have shown greater adverse effects of valproate exposure on verbal abilities compared with nonverbal abilities. ${ }^{141-144}$ The magnitude of reduction in verbal IQ associated with valproate has been shown to be dose-dependent. ${ }^{142,144}$

Other studies have shown an association between in utero valproate exposure and worse neuromotor functioning in offspring of women with epilepsy. In a prospective study of children born to women with epilepsy who were exposed in utero to valproate $(n=44)$ or levetiracetam $(n=53)$, valproate-exposed children had worse performance on tests of motor skills, comprehension, and expressive language abilities than levetiracetam-exposed children, whereas no significant differences in these measures were observed between children exposed in utero to levetiracetam and unexposed control children. ${ }^{145}$ Similar findings were reported from an ongoing prospective cohort study of 333 children exposed to anticonvulsant drugs in utero. ${ }^{146}$ At 18 months of age, anticonvulsant-exposed children had increased risk of abnormal gross motor performance (OR 2.2, 95\% CI 1.1-4.2) and sentence skills (OR 2.1, 95\% CI 1.2-3.6). Interestingly, the use of preconceptional folate use was associated with higher verbal performance than absence of periconceptional folate use in offspring or women with epilepsy who took anticonvulsants during pregnancy. ${ }^{147}$

A link between in utero exposure to valproate and impaired adaptive and emotional/behavioral functioning has also been shown in offspring of women with epilepsy. ${ }^{148}$ In a cohort study of 195 children who were exposed in utero to anticonvulsants, antenatal valproate exposure was associated with significantly lower General Adaptive Composite scores than children exposed to lamotrigine or phenytoin. ${ }^{148}$ There were also significant dose-related declines in adaptive functioning based on Adaptive Behavior Assessment System second edition parental ratings for both valproate and phenytoin. Valproate-exposed children exhibited significantly more atypical behaviors and inattention based on parental ratings on the Behavior Assessment System for Children compared with those exposed to lamotrigine or phenytoin groups. Indeed, others have found an association between in utero valproate exposure and developmental delay, mental retardation diagnosis, special education needs, and autism-spectrum disorder diagnoses in offspring of women with epilepsy, ${ }^{146,149-152}$ particularly in children who manifest dysmorphism patterns consistent with fetal valproate syndrome. ${ }^{153,154}$

\section{Carbamazepine}

\section{Major congenital malformations}

For many years, teratogenic risk with carbamazepine was regarded as being very high; however, more recent data challenge this assumption. The overall risk of any major congenital malformation with carbamazepine monotherapy is estimated as $3 \%-6 \%$, based on a review of six registrybased studies of women with epilepsy. ${ }^{120}$ Additional data are from a recent systematic review of eight cohort studies that included 2,680 pregnancies that involved carbamazepine monotherapy exposure in the first trimester. ${ }^{155}$ In that report, overall prevalence for any major congenital malformation was estimated at 3.3\%. This is lower than reported major congenital malformation rates $(5.3 \%)$ from a pooled analysis of older prospective cohort studies totaling 1,106 children 
with in utero exposure to carbamazepine monotherapy, although included studies employed different definitions of major congenital malformations. ${ }^{156}$

Overall malformation rates in offspring with firsttrimester carbamazepine exposure are much lower than corresponding rates with valproate. ${ }^{157}$ For example, in a prospective cohort study of 3,607 pregnant women with epilepsy, carbamazepine monotherapy was associated with the lowest risk of congenital malformations $(2.2 \%)$ compared with valproate $(6.2 \%)$, lamotrigine $(3.2 \%)$, and no anticonvulsant drug treatment $(3.5 \%) .{ }^{117}$ One large study documented a statistically significant association between the maternal daily dose of carbamazepine monotherapy and the risk of fetal malformations, ${ }^{119}$ while others have shown greater increases in fetal malformation risk with exposure to carbamazepine combined with valproate compared with carbamazepine alone. ${ }^{134,156,158}$ These studies provide additional evidence of lower major congenital malformation risk with in utero exposure to carbamazepine than valproate.

Similar to valproate, the most frequently reported individual major congenital malformations associated with in utero carbamazepine exposure are neural tube defects, such as spina bifida, although rates of neural tube defects in offspring of carbamazepine-treated women with epilepsy are much lower than corresponding rates with valproate. One report suggests that the use of periconceptional folate may lower the risk of neural tube defects among offspring of women who take carbamazepine during pregnancy. ${ }^{159}$ Other types of individual congenital malformations have been associated with carbamazepine. A meta-analysis of five prospective studies (1,255 exposed pregnancies) reported a significantly increased risk of neural tube defects, cleft palate, cardiovascular abnormalities, and urinary tract abnormalities. ${ }^{156}$ Rates of nearly all of these malformations are lower than corresponding rates with valproate. ${ }^{155}$ Individual studies also describe a constellation of craniofacial defects associated with in utero carbamazepine exposure that includes short nose, long philtrum, epicanthic folds, hypertelorism, upslanting palpebral fissures, and fingernail hypoplasia. ${ }^{160-163}$

\section{Adverse neonatal events}

The use of carbamazepine in late pregnancy has been associated with reports of transient hepatotoxicity, microcephaly, growth retardation, small-for-gestational-age delivery, vitamin $\mathrm{K}$ deficiency, coagulopathy, and low 1-minute Apgar scores. ${ }^{134,164,165}$ Rates of small-for-gestational-age delivery were significantly lower with carbamazepine than valproate in a prospective cohort study reviewed earlier, which involved
329 women with epilepsy (93 exposed children) who received antenatal anticonvulsant monotherapy. ${ }^{140}$

\section{Neurodevelopmental outcomes}

The overall risk of adverse neurodevelopmental outcomes with in utero carbamazepine exposure is uncertain. Some studies have shown variable degrees of developmental delay in offspring born to women with epilepsy who took carbamazepine. ${ }^{160,166}$ However, many other studies have yielded negative results. ${ }^{121,142,143,152,167}$ At least one prospective study showed that verbal performance at age 3 years was worse with increasing maternal carbamazepine doses during pregnancy. ${ }^{147}$ However, this correlation was not apparent at 6 years of age. ${ }^{141}$

\section{Lamotrigine}

\section{Major congenital malformations}

The overall risk of any major congenital malformation with lamotrigine monotherapy is estimated at $2 \%-3 \%$, based on a systematic review of several more recent registry-based studies of women with epilepsy. ${ }^{120}$ Therefore, it is not clear if lamotrigine monotherapy increases the risk of major congenital malformations above background rates found in the general population. ${ }^{168}$ Early studies focused on rates of any major congenital malformation were negative, ${ }^{168-171}$ while other individual reports have suggested possible small increases in the risk of oral clefts, hypospadias, and gastrointestinal defects. ${ }^{17,172,173}$ Other registry studies reported lower rates of oral clefts that fall generally within the range for offspring with no drug exposures. ${ }^{117,122,171,174}$ This includes results of a population-based cohort study of nearly 838,000 live births in Denmark, which found no increased risk of major birth defects with in utero exposure to lamotrigine $(1,019$ exposed deliveries) compared with no drug exposure (OR 1.18, 95\% CI 0.83-1.68). ${ }^{175}$ As mentioned earlier, some studies have suggested a higher risk of congenital malformations with higher maternal daily doses of lamotrigine ${ }^{117,119}$; however, the majority of reports have shown no dose-related effect. ${ }^{123,170,172,176,177}$ Congenital malformation rates have been shown to be lower with in utero exposure to lamotrigine than valproate, and slightly lower than carbamazepine. ${ }^{177}$ Data from the International Lamotrigine Pregnancy Registry have shown that rates of major congenital malformations were substantially higher with lamotrigine when combined with valproate compared with lamotrigine alone (10.7\% versus $2.8 \%) .{ }^{170}$ In that study, 35 infants with major congenital malformations were observed among 1,558 lamotrigine exposures during the first trimester over an 18-year period. No consistent patterns 
of specific malformations of dose-dependent increases in malformation risk were observed.

\section{Adverse neonatal events}

It is not yet clear if lamotrigine is associated with increased rates of adverse neonatal events.

\section{Neurodevelopmental outcomes}

Data regarding the risk of adverse neurodevelopmental and behavioral outcomes have been reassuring thus far. ${ }^{141,152,171}$ There has been no evidence of dose-dependent increases in the occurrence of problems with adaptive and emotional/ behavioral functioning, or dose-dependent increases in the risk of neurodevelopmental disorder diagnoses up to the age of 6 years.

\section{Antipsychotic drugs}

\section{Major congenital malformations}

Based on two systematic reviews of observational studies and case literature, there is no clear evidence of an association between typical or atypical antipsychotic drugs and major congenital malformations. ${ }^{178,179}$ Among the typical antipsychotics, reproductive safety risks are best understood for haloperidol, chlorpromazine, and perphenazine. ${ }^{178}$ For example, in a prospective study of 188 pregnancies exposed to haloperidol and 27 to penfluridol, major congenital malformation rates in both exposure groups combined (3.4\%) approximated major malformation rates in the general population, and did not differ statistically in comparison to that of 631 unexposed control pregnancies (3.8\%). ${ }^{180}$

Data regarding atypical antipsychotic exposure and the risk of congenital malformations are limited to mainly postmarketing surveillance and case reports. For example, of 713 risperidone-exposed pregnancies (68 during the first trimester) identified in the Benefit Risk Management Worldwide Safety Database, a register established by the a division of JNJ Pharmaceutical Research and Development, only two $(2.9 \%)$ cases of major congenital malformations were identified. ${ }^{181}$ A review of pregnancy reports in the Eli Lilly Worldwide Pharmacovigilance Safety Database identified no cases of major congenital malformations, but included only 23 prospectively identified cases. ${ }^{182}$ There is a paucity of information regarding congenital malformation risk from large, well-controlled prospective studies. The largest prospective study comparing pregnancy outcomes among 151 pregnant women with atypical antipsychotic drug exposure included only 60 exposures to olanzapine, 49 to risperidone, 36 to quetiapine, and six to clozapine. ${ }^{183}$ Among the antipsychotic-exposed pregnancies, there was only one $(0.9 \%)$ major congenital malformation.

One retrospective population-based study used data from the Swedish Medical Birth Register. ${ }^{184}$ Antipsychotic use was split into two exposure groups: use of dixyrazine or prochlorperazine irrespective of use of any other antipsychotics (used commonly for treating nausea and vomiting in pregnancy) and "other antipsychotics". Women using lithium were excluded. All main analyses were adjusted for birth year, parity, smoking, and prior miscarriage. The risk of any congenital malformation was not increased in either exposure group compared with all registered births. After restricting the analysis to include only severe malformations, the "other antipsychotics" group had a slightly higher risk (OR 1.52, 95\% CI 1.05-2.19); however, after the exclusion of women who reported concomitant use of anticonvulsants during pregnancy, the risk estimate was no longer statistically significant (OR 1.45, 95\% CI 0.99-1.41).

Reproductive safety data for quetiapine are limited primarily to the study by McKenna et al reviewed earlier, which included only 36 exposures. ${ }^{183}$ Other reproductive outcomes are reported in the case literature only, and report no adverse effects in terms of obstetric or fetal outcome. ${ }^{185-188}$ Very few reports exist concerning reproductive safety outcomes of aripiprazole, ziprasidone, asenapine, or lurasidone. ${ }^{189}$ Preliminary data from the National Register of Antipsychotic Medication in Pregnancy in Australia, a voluntary pregnancy registry established in 2005, included two cases of high neural tube defects that resulted in early second-trimester miscarriage in women who received aripiprazole during pregnancy. ${ }^{190}$

\section{Adverse neonatal events}

Both typical and atypical antipsychotics have been associated with perinatal complications, including extrapyramidal signs, respiratory distress, seizures, feeding difficulties, tachycardia, low blood pressure, and transient neurodevelopmental delay. ${ }^{178}$ Self-limited extrapyramidal signs and tremor, jitteriness, irritability, feeding problems, and somnolence have been reported separately for antenatal risperidone exposure. ${ }^{181}$ In 2011, the US Food and Drug Administration (FDA) released a drug-safety communication alerting health care professionals to updates of the pregnancy section of drug labels for all antipsychotic drugs that included warnings about the potential risk for extrapyramidal signs and "withdrawal symptoms" in newborns of mothers who received antipsychotic treatment during the third trimester of pregnancy (http://www.fda.gov/Drugs/DrugSafety/ ucm243903.htm). ${ }^{191}$ These warnings were based on a search 
of the US FDA Adverse Event Reporting System database that identified 69 spontaneously reported cases of neonatal extrapyramidal signs or withdrawal with all antipsychotic drugs. The symptoms varied in severity, with infants recovering within hours or days and requiring no specific treatment. Other cases involved recovery in neonatal intensive care units or resulted in prolonged hospitalization. Most cases involved potential confounding factors, including premature delivery, preeclampsia and other pregnancy complications, and concomitant exposure to other drugs associated with withdrawal symptoms (eg, antidepressants, benzodiazepines, nonbenzodiazepine hypnotics, and opioids).

The well-known risk of clinically significant weight gain and adverse changes in glycemic profiles associated with some antipsychotic drugs prompted investigations into the risk of large-for-gestational-age delivery associated with antenatal antipsychotic drug exposure. ${ }^{192}$ A small study of prospectively collected data on gestational age and birth weight among 45 infants exposed in utero to typical antipsychotics, 25 infants exposed to atypical antipsychotics, and 38 unexposed controls. ${ }^{193}$ Higher incidence rates of large-for-gestational-age delivery were observed among infants exposed to atypical (20\%) than those exposed to typical antipsychotics (2\%) and no antipsychotics (3\%). In utero exposure to clozapine and olanzapine, the most orexigenic atypical antipsychotic drugs, was associated with higher mean birth weight compared with typical antipsychotic exposure, but not controls. Excluding cases with concomitant exposure to other weight-altering medications did not significantly change these findings. The results of this study were consistent with other reports of higher birth weight with antenatal olanzapine exposure compared with antenatal exposure to other psychotropic medications, ${ }^{194}$ but contrasted with those of another prospective study of 54 pregnant women with laboratory-confirmed use of olanzapine, haloperidol, risperidone, or quetiapine close to the time of delivery. ${ }^{195}$ In that study, statistical trends toward higher rates of low-birth-weight delivery and neonatal intensive care unit admission with olanzapine exposure were observed.

In a very large population-based retrospective cohort study of 169,338 antipsychotic-exposed and 357,696 -unexposed pregnancies, antipsychotic drug use during pregnancy was associated with an increased risk of gestational diabetes compared with the total population of births, after adjusting for birth order and maternal age, country of birth, cohabitation, smoking, and height (adjusted OR 1.77, 95\% CI 1.04-3.03). ${ }^{196}$ The effect-size estimate increased marginally after being restricted to only clozapine- and olanzapine-exposed pregnancies (adjusted OR 1.94, 95\% CI 0.97-3.91), although the risk was not statistically significant. The adjusted OR of large-for-gestational-age delivery by head circumference was significantly increased for olanzapine- and clozapine-exposed infants (3.02, 95\% CI 1.60-5.71); however, antenatal antipsychotic drug exposure was not associated with significantly higher risk of small-for-gestational-age delivery or large-forgestational-age delivery on the basis of birth weight or birth length in adjusted analyses.

\section{Neurodevelopmental outcomes}

There have been very few investigations of possible adverse neurodevelopmental outcomes in children with in utero exposure to antipsychotic drugs. In one prospective controlled study of 309 mother-infant dyads evaluated at 6 months postpartum, 22 involved pregnancy exposure to antipsychotics, 202 to antidepressants, and 85 to no psychotropic drugs. ${ }^{197}$ Infants with prenatal antipsychotic drug exposure had significantly lower neuromotor-performance scores as measured by the Infant Neurological International Battery, a standardized assessment of posture, muscle tone, reflexes, and motor skills, in comparison with antidepressant-exposed children or children with no psychotropic exposure.

\section{Reproductive safety of nonpharmacological interventions}

Although not recommended as a stand-alone treatment, empirically supported psychotherapy has no known risks of for bipolar disorders during pregnancy. Antenatal administration of ECT has not been consistently associated with adverse effects on pregnancy or neonatal outcome in pregnant women or neonates. ${ }^{198-200}$ Sporadic cases of major malformations have been reported, with no clear pattern of malformations emerging. ${ }^{198}$ Although data are limited, drugs that are commonly used for anesthesia (methohexital, propofol), neuromuscular blockade (succinylcholine), and prevention of clinically significant bradycardia during the stimulation phase of ECT (glycopyrrolate) are not considered major human teratogens. ${ }^{201}$ Low rates of fetal bradycardia were reported in a systematic review of 339 cases summarizing outcomes of ECT administered during pregnancy. ${ }^{199}$

\section{Summary and clinical implications}

Treating women with bipolar spectrum disorders during pregnancy is one of the greatest clinical challenges in psychiatric practice. Although most studies show high recurrence rates during pregnancy, others have shown 
that some women may have remarkable stability during pregnancy, ${ }^{202,203}$ including fewer or shorter recurrences during pregnancy compared with before pregnancy. ${ }^{204}$ While there is still some controversy regarding whether or not pregnancy is a vulnerable period for the recurrence of mood episodes, ${ }^{205}$ there is no clear evidence that pregnancy protects women against bipolar relapses. The postpartum period is a well-known period of heightened bipolar episode-relapse risk, and a significant proportion of women with postpartum relapses may be symptomatic during the antepartum period. ${ }^{206}$

As reviewed earlier, results of most controlled observational studies provide support for continuing effective maintenance treatment with mood stabilizers, long considered core foundational bipolar disorder pharmacotherapies, for relapse prevention during pregnancy and the postpartum period. This is reassuring, given the crucial goal of maintaining maternal euthymia during pregnancy and the postpartum period, thereby protecting the mother and her children against the significant adverse outcomes associated with untreated or poorly treated illness. Recently documented increases in the use of mood-stabilizing anticonvulsants and atypical antipsychotics in pregnant women may reflect increased awareness of these risks among health care providers. ${ }^{25} \mathrm{On}$ the other hand, a fifth to a third of women who remain on mood stabilizers may still relapse during pregnancy. ${ }^{66-68} \mathrm{Con}-$ tinuation of pharmacotherapy with mood stabilizers during pregnancy, therefore, does not provide a guarantee against antepartum relapses.

In the past two decades, there has been an impressive accumulation of knowledge regarding congenital malformation and neonatal risk associated with anticonvulsant mood stabilizers, eg, valproate, carbamazepine, and lamotrigine. However, there are important caveats that make interpretation of this literature more difficult. Studies of lithium exposures consist mainly of women with bipolar disorder, but this is not so for anticonvulsant mood stabilizers. Indeed, nearly all reproductive safety studies of mood-stabilizing anticonvulsants were conducted using large cohorts of women with epilepsy, not women with bipolar disorder. It is often assumed that women with epilepsy have a higher risk than the general population for giving birth to a child with congenital malformations, independent of effects of anticonvulsant drugs. Under these circumstances, the congenital malformation risk associated with some anticonvulsants may be accounted for by the risks associated with seizure disorders (confounding by indication). On the other hand, a meta-analysis of ten studies (400 exposed pregnancies) found that the risk of major congenital malformations in offspring of women with untreated seizure disorders was not significantly higher than that of nonepileptic controls (OR 1.92, 95\% CI 0.82-4.00); however, offspring of women with epilepsy who received anticonvulsant drugs had a higher incidence of major congenital malformations compared with controls (OR 3.26, 95\% CI 2.15-4.93). ${ }^{207}$ The crucial questions of whether or not the bipolar disorder itself or factors associated with bipolar disorder diagnoses (obesity, smoking, substance abuse, self-neglect during depressive episodes, other negative health behaviors, etc) are independently associated with an increased risk of congenital malformations or adverse neonatal events, or whether risks associated with bipolar disorders are different than those associated with epilepsy, require additional study.

The epidemiological literature points consistently to significantly higher rates of major congenital malformations, adverse neonatal events, and concerning neurodevelopmental difficulties with in utero exposure to valproate, relative to other anticonvulsants and background rates of these outcomes, in offspring of treated women with epilepsy. These findings have been consistently shown across numerous cohorts and data sources, and these risks appear to increase with increasing maternal daily valproate dose during pregnancy and with the concomitant use of valproate with other anticonvulsants. Rates of overall and specific malformations with valproate are also much higher than those associated with lithium, the latter of which appear to be associated with rarely occurring cases of cardiac defects, including Ebstein's anomaly. Overall and specific congenital malformation rates with carbamazepine are substantially lower than those associated with valproate, and may be comparable to those associated with lamotrigine, the latter of which approximate background congenital malformation rates in the general population. Thus far, there has been little or no evidence of an increased risk of adverse effects on neurodevelopment associated with in utero exposure to carbamazepine, lamotrigine, or lithium, although additional studies focused on these risks in exposed offspring of women with bipolar disorders are needed.

It is not yet clear if folate supplementation or the use of only modest doses of valproate or other anticonvulsant mood stabilizers reduces the risk of neural tube defects or other congenital malformations in offspring of women with bipolar disorder. Keeping the daily dose of valproate as low as possible (below 1,000 mg) and supplementing with folate, for example, have both been advocated. ${ }^{208}$ But results of several large pregnancy-registry studies and one recent 
case-control study do not support a role of maternal folate supplementation for reducing the risk of congenital malformations in exposed offspring. ${ }^{119,209-211}$ In one of the largest registry studies, folate supplementation was associated with a greater risk of major congenital malformations, although confounding by indication seems likely, because women at greater risk of delivering an infant with congenital malformations may be more likely to take folate. ${ }^{119}$ Folic acid $0.4 \mathrm{mg}$ daily is recommended for women of reproductive age, including those who have delivered babies with neural tube defects, to prevent spina bifida and anencephaly, ${ }^{212}$ although some have advocated for higher doses, eg, $4 \mathrm{mg}$ daily, in the setting of anticonvulsant treatment during pregnancy. ${ }^{213,214}$ Initial evidence of a protective effect of preconceptional folate use on verbal IQ, relative to absence of periconceptional folate use, in offspring of women with epilepsy who took anticonvulsants during pregnancy is intriguing, but awaits further confirmation. ${ }^{147}$

In the last 15 years, atypical antipsychotic drugs have been increasingly used to treat bipolar disorder, and have supplanted the foundational mood stabilizers as the leading form of bipolar disorder pharmacotherapy. ${ }^{215-217}$ While selected atypical antipsychotics have demonstrated broad-spectrum efficacy for treating both acute bipolar mood episodes and preventing their recurrence, ${ }^{17,59,64}$ none have been well studied during pregnancy. However, given the known reproductive safety risks of some classical mood stabilizers, atypical antipsychotics with established mood-stabilizing properties may be regarded by many as an attractive alternative for treating bipolar disorders in the context of pregnancy. Increased use of atypical antipsychotics during pregnancy ${ }^{24,25}$ appears to be accounted for primarily by pregnant women with diagnosed affective disorders, including bipolar disorder. ${ }^{24}$ On the other hand, the reproductive safety of atypical antipsychotics as a group and of individual agents is far less clear than that of most mood stabilizers. Better understood is the risk of clinically significant weight gain and adverse metabolic profile of several antipsychotic drugs in nonpregnant populations, including increased risk of new-onset type 2 diabetes mellitus. ${ }^{192,218,219}$ Excessive weight gain, maternal diabetes mellitus, and gestational diabetes are important risk factors for congenital malformations, including neural tube and cardiac defects. $^{220-225}$ Therefore, the impact of antipsychotic use on maternal weight gain and glycemic homeostasis in pregnant women are important areas for future research.

Bipolar disorders were once regarded as episodic illnesses characterized by complete interepisode recovery. Subsequent data from longitudinal studies showed that many patients with bipolar disorders experience chronic, persisting, and clinically significant mood symptoms in between acute mood episodes, mainly in the depressive pole., ${ }^{226}$ Additionally, for many patients, mood-stabilizer monotherapy may be insufficient for preventing bipolar mood relapses. ${ }^{227}$ These factors have likely contributed to increases in the use of combination pharmacotherapy for long-term management of bipolar disorders. ${ }^{228,229}$ Limitations of monotherapy have also been recognized in practice guidelines for treating bipolar disorder in pregnancy, which recommend monotherapy whenever possible to minimize fetal drug exposure and combination pharmacotherapy for more difficult-to-treat cases. ${ }^{230}$ On the other hand, fetal exposure to multiple medications may increase the risk of adverse outcomes, and this may be particularly so for combinations involving the use of valproate.

Clinical decision making about the use of mood stabilizers and atypical antipsychotics by pregnant women can be conceptualized as balancing the competing risks imposed by withholding or stopping pharmacotherapeutic treatment (thus increasing the risk of maternal and fetal/neonatal harm from untreated illness or acute relapses) against that of continuing or initiating pharmacotherapy during pregnancy (thus introducing the possibility of fetal/neonatal harm associated with in utero medication exposure). The literature addressing these safety issues has been criticized as being overfocused on the risk of drug treatment at the expense of those associated with un- or undertreated bipolar disorders or potential positive impact of treatment. ${ }^{208,231}$ Additional research regarding best practices for optimizing treatment of women with bipolar disorder during pregnancy is urgently needed, but studies of this type are difficult to conduct. Randomized trials cannot be used to answer crucial questions about the comparative effectiveness and reproductive safety of medications used to treat bipolar disorders when administered during pregnancy due to ethical concerns. Prospective cohort studies of fetal and neonatal safety are often infeasible, or results of existing studies difficult to interpret, given the large numbers of participants required to have a sufficient number of events for valid analysis. ${ }^{232}$

Despite these and other challenges, high-quality practice guidelines for managing bipolar disorders in pregnant and postpartum women have been developed, ${ }^{22,230,233,234}$ and treatment considerations for this population are covered in general bipolar disorder-treatment guidelines. ${ }^{77,90,235,236}$ A detailed review of recommended approaches for treating acute mood episodes or preventing their recurrence during pregnancy is beyond the scope of this review. However, some of these 
guidelines provide consistent recommendations in several key areas, ${ }^{237}$ including the importance of discussing reproductive and obstetric risks associated with pharmacotherapies in all women with bipolar disorder who are of reproductive age, even prior to formal preconception planning. This point is crucial, given the high rates of unplanned pregnancies among patients with bipolar disorders. ${ }^{238,239}$ Maximizing nonpharmacological treatments, social supports, and regularity of sleep and biological rhythms is also advocated. ${ }^{22}$ Practice guidelines consistently advise the use of monotherapy (as opposed to combination therapies) at the lowest effective dose, avoidance of first-trimester use of valproate whenever possible to minimize teratogenic potential, and use of ECT for severe or refractory symptoms. ${ }^{240}$ Notable differences in clinical recommendations exist across guidelines, including avoidance or continuation of lithium and the degree to which atypical antipsychotic treatment is prioritized, ${ }^{237}$ highlighting the need for additional study of the pharmacological treatment of pregnant women with bipolar disorder.

For the management of acute mania during pregnancy, haloperidol may be preferred for many women, based on its established efficacy in randomized trials involving nonpregnant patients compared to other typical neuroleptics or atypical antipsychotics (due to fewer reproductive safety data) or antimanic mood stabilizers (due to reproductive safety concerns). ${ }^{59,178,179}$ Lithium or ECT can be used to treat acute manic episodes during pregnancy that are unresponsive to typical or atypical antipsychotic drugs ${ }^{89}$ Some patients may ultimately need a combination of a mood stabilizer and antipsychotic drug to achieve stability.

For the management of acute bipolar depression during pregnancy, lamotrigine may be preferred, given the reasonable efficacy in nonpregnant patients ${ }^{63}$ and reassuring reproductive safety data compared to moodstabilizing atypical antipsychotics (due to fewer reproductive safety data) and lithium. Quetiapine, olanzapine, olanzapine + fluoxetine, and lithium may be considered second-line therapeutic options. Some patients will require combination pharmacotherapeutic regimens to achieve clinical stability. The reproductive safety profile is unknown for lurasidone, an atypical antipsychotic drug recently approved for treating acute bipolar I depression in nonpregnant patients (as a monotherapy or in combination with lithium or valproate). ${ }^{65,66}$ Unlike acute mania, there is no evidence clearly supporting the use of typical neuroleptics, such as haloperidol, for treating acute bipolar depression. Psychotherapy is recommended as an adjunct to medication treatment of acute bipolar depression during pregnancy. ${ }^{22,80}$ Similarly to acute mania, pharmacoresistant cases of acute bipolar depression may respond to $\mathrm{ECT}{ }^{87}$

Challenges arise for women with bipolar disorder who are pregnant and are stable on maintenance pharmacotherapy. For patients who are currently stable, the factors to consider when deciding whether or not to continue effective maintenance treatment during pregnancy include the number of lifetime bipolar mood episodes, severity of past episodes (including the presence of psychotic features and suicide attempts), psychotic comorbidities (particularly anxiety and substanceuse disorders), medical illnesses, past treatment response, (during prior gravid and nongravid periods), time to relapse after prior discontinuation of maintenance treatment (and time to recovery following reinitiation of pharmacotherapy), level of residual symptomatology (and current impact on functioning), and the reproductive and lactational safety profile of current treatments. With the assumption that specific pharmacotherapies have been effective, continuing medications during pregnancy may be appropriate if the risk of prenatal exposure is outweighed by the risk of relapse with drug discontinuation. ${ }^{241}$ Ultimately, the decision will often depend on individual patient preferences and values regarding the reproductive safety of available therapeutic options and the potential consequences of untreated illness.

Some women with stable longitudinal courses with prolonged periods of euthymia and good psychosocial support can be managed with close monitoring and follow-up when off of medications. ${ }^{242}$ If medication is to be discontinued, it should be done so gradually if possible, with vigilance for early signs of relapse, especially with lithium. ${ }^{44}$ For those with histories of relapses during interruptions in drug treatment, unstable longitudinal courses despite maintenance pharmacotherapy, or histories of severe postpartum affective or psychotic episodes, medication treatment during at least some stages of pregnancy may be needed..$^{234,242}$ For euthymic patients, lamotrigine may be considered a high-priority option based on relatively reassuring reproductive safety data and established maintenance-phase efficacy in randomized trials of nonpregnant patients. Lithium, quetiapine, and other selected atypical antipsychotic drugs may be considered as second-line agents; however, it is generally best to use medications that have resulted in clinical improvement and stability. ${ }^{243}$ It is also generally prudent to monitor mood-stabilizer levels, including lithium and lamotrigine, throughout pregnancy, since maternal drug concentrations can fluctuate significantly during pregnancy and during the early postpartum period. ${ }^{109,244-246}$ If possible, valproate should be avoided during 
pregnancy, due to structural and neurobehavioral teratogenic risk, unless it is clear that valproate is required in order to maintain clinical stability. ${ }^{230}$ The use of antidepressants for bipolar maintenance is controversial, owing to limited clinical effectiveness as adjuncts to mood stabilizers in large randomized trials and the potential risk of treatment-emergent polar mood switching and mood-cycle acceleration ${ }^{247,248}$; however, for some patients, they are beneficial for preventing bipolar depressive relapses. ${ }^{249,250}$ Although monotherapy with a mood stabilizer or atypical antipsychotic known to be effective for bipolar maintenance treatment is preferred, combination pharmacotherapy may be needed to maintain mood stability and prevent severe relapses. ${ }^{2,248,251}$

Increasing evidence of adverse neurodevelopmental effects in offspring of epileptic mothers who received valproate treatment while pregnant provides additional reasons to avoid valproate, if possible, during any stage of pregnancy. There are situations, however, where these general guidelines cannot be followed, because of severe and highly unstable illness that cannot be successfully managed without valproate. Although congenital malformation rates are lower with carbamazepine, it is associated with other potential problems that warrant due caution, including a small but significant risk of congenital malformations, a less established role in the long-term maintenance treatment of bipolar disorder than many other agents, and the accelerated metabolism of it and other drugs owing to the induction of key drug-metabolizing enzymes. ${ }^{252}$ There is not yet clear evidence that administering vitamin $\mathrm{K}$ analogs to mothers reduces the risk of neonatal hemorrhagic events with the use of carbamazepine (and other enzyme-inducing anticonvulsants). ${ }^{253}$ For many women who require mood stabilizers, lithium or lamotrigine may end up being the safest choices. Lithium is associated with cardiac defects, but the absolute risk appears to be very small. Still, for lithiumtreated pregnant women, high-resolution ultrasound and fetal echocardiography are recommended. ${ }^{233}$ Prenatal surveillance for congenital malformations is also recommended for women who receive valproate, carbamazepine, or lamotrigine, which may include maternal serum $\alpha$-fetoprotein, fetal echocardiography, and high-resolution ultrasound. ${ }^{233}$ Valproate and carbamazepine are generally considered compatible with breastfeeding, whereas lithium is not. ${ }^{254-256}$ Lactational risks associated with lamotrigine are unknown.

Information on the reproductive safety of mood-stabilizing atypical antipsychotic drugs is very limited beyond risperidone, olanzapine, and quetiapine. ${ }^{178}$ Available data concerning the teratogenic risks associated with typical neuroleptics are reassuring; however, typical neuroleptics are ineffective for managing - and may even worsen depressive symptoms in patients with bipolar disorder. ${ }^{257,258}$ Moreover, typical neuroleptics are associated with higher long-term risk of tardive dyskinesia than atypical antipsychotics, ${ }^{259}$ and may be associated with increased risk for extrapyramidal side effects in neonates. ${ }^{178}$ Secondary increases in reproductive risk mediated by excessive weight gain or disturbances in glucose handling associated with some antipsychotic drugs are potential risks that need to be explored in future studies. Changes in body weight and screening for increases in blood glucose should be closely followed in pregnant women and all women of reproductive age who receive antipsychotic treatment, particularly with atypical antipsychotic drugs.

\section{Limitations}

The limitations of this review reflect the limitations of the existing literature. The unavailability of randomized controlled studies and lack of studies using large cohorts of pregnant women with diagnoses of bipolar disorder, as opposed to those with epilepsy, have already been highlighted as major limitations. The best available evidence upon which to base clinical decisions about relative safety and the effectiveness of bipolar disorder pharmacotherapy during pregnancy comes from controlled cohort studies. ${ }^{109}$ Many prospective cohort studies, as discussed earlier, have lacked the statistical power to permit meaningful comparisons in the incidence rates of rare events, such as specific major congenital malformations.

Although very large-scale retrospective cohort studies can overcome limitations in statistical power for these rare events, confounding by indication and end-point misclassification are important potential threats to validity, particularly in largescale studies using automated claims and other computerized health outcome databases. The validity of diagnostic codes to identify cases of major congenital malformations, for instance, can vary considerably depending on the data source and organ system involved, and many defects are likely to require confirmation (eg, by review of medical records) in order to be validly identified. ${ }^{260}$ Although automated records of filled prescriptions provide a reasonably complete and inexpensive account of potential drug exposures, it is also true that medication ingestion cannot be verified in most cases. This is crucial for the conduct of studies of drug exposure in pregnant women with bipolar disorder and other affective disorders, because many women stop medications due to fears of teratogenic risk. ${ }^{203}$

These limitations may be partially addressed by the use of drug- and disease-specific pregnancy registries. These types 
of studies have been crucial to our understanding of the risks of congenital malformations and adverse neurocognitive outcomes in offspring of women with epilepsy who received anticonvulsant treatment while pregnant. Registry-based studies also have significant limitations, however, including voluntary participation and referral bias, which may have resulted in overrepresentation of mothers with more severe epilepsy and those who delivered infants with congenital abnormalities. ${ }^{208,261}$ Very few registry-based data are available at present for atypical antipsychotics or for women with bipolar disorder.

In conclusion, treating women with bipolar spectrum disorders during pregnancy is a common and highly formidable challenge in clinical practice. This is particularly so regarding decisions about pharmacological treatment. Risks to both mother and baby are imposed by untreated or undertreated bipolar illness and by the use of pharmacotherapy. Continuation of effective pharmacotherapy during pregnancy can prevent relapses, although not every woman who continues effective medications will remain relapse-free during pregnancy. As such, there are no uniformly effective or riskfree treatment options. It is perhaps more pragmatically useful to move clinical reasoning beyond simple choices of whether or not to treat maternal bipolar disorder during pregnancy to how exposures to potential harms from bipolar relapses, clinically significant residual symptoms, and medications may be minimized. Indeed, fully informed decision making requires that the risks of both untreated maternal bipolar disorder and risks associated with each potential intervention be reviewed, and that all reasonable treatment options be discussed.

\section{Disclosure}

The authors report no conflicts of interest in this work. In the past, WVB has received grants/research support from Cephalon and has served on speaker panels for Janssen Pharmaceutica and Pfizer. Except as disclosed above: 1) none of the authors are current or former employees of or consultants to a company whose product(s) is/are discussed in this manuscript, 2) none of the authors have stock or stock options in a company whose product(s) is/are discussed in this manuscript, and 3) none of the authors are members of a speakers' bureau for a company whose product(s) is/are discussed in this article.

\section{References}

1. Belmaker RH. Bipolar disorder. N Engl J Med. 2004;351:476-486.

2. Judd LL, Akiskal HS, Schettler PJ, et al. The long-term natural history of the weekly symptomatic status of bipolar I disorder. Arch Gen Psychiatry. 2002;59:530-537.
3. Kleinman L, Lowin A, Flood E, Gandhi G, Edgell E, Revicki D. Costs of bipolar disorder. Pharmacoeconomics. 2003;21:601-622.

4. Dean BB, Gerner D, Gerner RH. A systematic review evaluating health-related quality of life, work impairment, and healthcare costs and utilization in bipolar disorder. Curr Med Res Opin. 2004;20: $139-154$.

5. Stensland MD, Jacobson JG, Nyhuis A. Service utilization and associated direct costs for bipolar disorder in 2004: an analysis in managed care. J Affect Disord. 2007;101:187-193.

6. Tohen M, Zarate CA Jr, Hennen J, et al. The McLean-Harvard FirstEpisode Mania Study: prediction of recovery and first recurrence. Am J Psychiatry. 2003;160:2099-2107.

7. Goldberg JF, Harrow M. Consistency of remission and outcome in bipolar and unipolar mood disorders: a 10-year prospective follow-up. JAffect Disord. 2004;81:123-131.

8. Rihmer Z, Angst J. Mood disorders: epidemiology. In: Sadock BJ, Sadock VA, Ruiz P, editors. Kaplan and Sadock's Comprehensive Textbook of Psychiatry. 9th ed. Philadelphia: Lippincott Williams \& Wilkins; 2009:1645-1652.

9. Bauer M, Pfennig A. Epidemiology of bipolar disorders. Epilepsia. 2005;46 Suppl 4:8-13.

10. Angst J, Gamma A, Lewinsohn P. The evolving epidemiology of bipolar disorder. World Psychiatry. 2002;1:146-148.

11. Kessler RC, Chiu WT, Demler O, Merikangas KR, Walters EE. Prevalence, severity, and comorbidity of 12-month DSM-IV disorders in the National Comorbidity Survey Replication. Arch Gen Psychiatry. 2005;62:617-627.

12. Fountoulakis KN, Vieta E. Treatment of bipolar disorder: a systematic review of available data and clinical perspectives. Int $J$ Neuropsychopharmacol. 2008;11:999-1029.

13. American Psychiatric Association. Practice guideline for the treatment of patients with bipolar disorder (revision). Am J Psychiatry. 2002;159: $1-50$.

14. Judd LL, Akiskal HS, Schettler PJ, et al. The comparative clinical phenotype and long term longitudinal episode course of bipolar I and II: a clinical spectrum or distinct disorders? J Affect Disord. 2003;73: $19-32$.

15. Gitlin MJ, Swendsen J, Heller TL, Hammen C. Relapse and impairment in bipolar disorder. Am J Psychiatry. 1995;152:1635-1640.

16. Scott J, Pope M. Self-reported adherence to treatment with mood stabilizers, plasma levels, and psychiatric hospitalization. $\mathrm{Am} \mathrm{J}$ Psychiatry. 2002;159:1927-1929.

17. Gitlin M, Frye MA. Maintenance therapies in bipolar disorders. Bipolar Disord. 2012;14 Suppl 2:51-65.

18. Suppes T, Leverich GS, Keck PE, et al. The Stanley Foundation Bipolar Treatment Outcome Network. II. Demographics and illness characteristics of the first 261 patients. J Affect Disord. 2001;67:45-59.

19. Kennedy N, Boydell J, Kalidindi S, et al. Gender differences in incidence and age at onset of mania and bipolar disorder over a 35-year period in Camberwell, England. Am J Psychiatry. 2005;162:257-262.

20. Vesga-López O, Blanco C, Keyes K, Olfson M, Grant BF, Hasin DS. Psychiatric disorders in pregnant and postpartum women in the United States. Arch Gen Psychiatry. 2008;65:805-815.

21. Blehar MC, DePaulo JR Jr, Gershon ES, Reich T, Simpson SG, Nurnberger JI Jr. Women with bipolar disorder: findings from the NIMH Genetics Initiative sample. Psychopharmacol Bull. 1998;34: 239-243.

22. Yonkers KA, Vigod S, Ross LE. Diagnosis, pathophysiology, and management of mood disorders in pregnant and postpartum women. Obstet Gynecol. 2011;117:961-977.

23. Viguera AC, Tondo L, Koukopoulos AE, Reginaldi D, Lepri B, Baldessarini RJ. Episodes of mood disorders in 2,252 pregnancies and postpartum periods. Am J Psychiatry. 2011;168:1179-1185.

24. Toh S, Li Q, Cheetham TC, et al. Prevalence and trends in the use of antipsychotic medications during pregnancy in the US, 2001-2007: a population-based study of 585,615 deliveries. Arch Womens Ment Health. 2013;16:149-157. 
25. Epstein RA, Bobo WV, Shelton RC, et al. Increasing use of atypical antipsychotics and anticonvulsants during pregnancy. Pharmacoepidemiol Drug Saf. 2013;22:794-801.

26. Baldessarini RJ, Leahy L, Arcona S, Gause D, Zhang W, Hennen J. Patterns of psychotropic drug prescription for US patients with diagnoses of bipolar disorders. Psychiatr Serv. 2007;58:85-91.

27. Pacchiarotti I, Bond DJ, Baldessarini RJ, et al. The International Society for Bipolar Disorders (ISBD) task force report on antidepressant use in bipolar disorders. Am J Psychiatry. 2013;170:1249-1262.

28. Brunette MF, Noordsy DL, Xie H, Drake RE. Benzodiazepine use and abuse among patients with severe mental illness and co-occurring substance use disorders. Psychiatr Serv. 2003;54:1395-1401.

29. Rosa AR, Fountoulakis K, Siamouli M, Gonda X, Vieta E. Is anticonvulsant treatment of mania a class effect? Data from randomized clinical trials. CNS Neurosci Ther. 2011;17:167-177.

30. Jablensky AV, Morgan V, Zubrick SR, Bower C, Yellachich LA. Pregnancy, delivery, and neonatal complications in a population cohort of women with schizophrenia and major affective disorders. Am J Psychiatry. 2005;162:79-91.

31. Lee HC, Lin HC. Maternal bipolar disorder increased low birthweight and preterm births: a nationwide population-based study. $J$ Affect Disord. 2010;121:100-105.

32. Bodén R, Lundgren M, Brandt L, Reutfors J, Andersen M, Kieler H. Risks of adverse pregnancy and birth outcomes in women treated or not treated with mood stabilisers for bipolar disorder: population based cohort study. BMJ. 2012;345:e7085.

33. Henin A, Biederman J, Mick E, et al. Psychopathology in the offspring of parents with bipolar disorder: a controlled study. Biol Psychiatry. 2005;58:554-561.

34. Hirshfeld-Becker DR, Biederman J, Henin A, et al. Psychopathology in the young offspring of parents with bipolar disorder: a controlled pilot study. Psychiatry Res. 2006;145:155-167.

35. Duffy A, Alda M, Crawford L, Milin R, Grof P. The early manifestations of bipolar disorder: a longitudinal prospective study of the offspring of bipolar parents. Bipolar Disord. 2007;9:828-838.

36. Munk-Olsen T, Laursen TM, Mendelson T, Pedersen CB, Mors O, Mortensen PB. Risks and predictors of readmission for a mental disorder during the postpartum period. Arch Gen Psychiatry. 2009;66: 189-195.

37. Kendell RE, Chalmers JC, Platz C. Epidemiology of puerperal psychoses. Br J Psychiatry. 1987;150:662-673.

38. Heron J, Haque S, Oyebode F, Craddock N, Jones I. A longitudinal study of hypomania and depression symptoms in pregnancy and the postpartum period. Bipolar Disord. 2009;11:410-417.

39. Jones I, Craddock N. Bipolar disorder and childbirth: the importance of recognising risk. Br J Psychiatry. 2005;186:453-454.

40. Akdeniz F, Vahip S, Pirildar S, Vahip I, Doganer I, Bulut I. Risk factors associated with childbearing-related episodes in women with bipolar disorder. Psychopathology. 2003;36:234-238.

41. Harlow BL, Vitonis AF, Sparen P, Cnattingius S, Joffe H, Hultman CM. Incidence of hospitalization for postpartum psychotic and bipolar episodes in women with and without prior prepregnancy or prenatal psychiatric hospitalizations. Arch Gen Psychiatry. 2007;64:42-48.

42. Valdimarsdóttir U, Hultman CM, Harlow B, Cnattingius S, Sparén P. Psychotic illness in first-time mothers with no previous psychiatric hospitalizations: a population-based study. PLoS Med. 2009;6:e13.

43. Jones I, Craddock N. Familiality of the puerperal trigger in bipolar disorder: results of a family study. Am J Psychiatry. 2001;158:913-917.

44. Curtis V. Women are not the same as men: specific clinical issues for female patients with bipolar disorder. Bipolar Disord. 2005;7 Suppl 1: $16-24$.

45. Regier DA, Farmer ME, Rae DS, et al. Comorbidity of mental disorders with alcohol and other drug abuse. Results from the Epidemiologic Catchment Area (ECA) study. JAMA. 1990;264:2511-2518.

46. Goldstein BI, Strober MA, Birmaher B, et al. Substance use disorders among adolescents with bipolar spectrum disorders. Bipolar Disord. 2008;10:469-478.

47. LIndahl V, Pearson JL, Colpe L. Prevalence of suicidality during pregnancy and the postpartum. Arch Womens Ment Health. 2005;8: 77-87.
48. Muralidharan K, Ali M, Silveira LE, et al. Efficacy of second generation antipsychotics in treating acute mixed episodes in bipolar disorder: a meta-analysis of placebo-controlled trials. J Affect Disord. 2013;150:408-414.

49. Yildiz A, Vieta E, Leucht S, Baldessarini RJ. Efficacy of antimanic treatments: meta-analysis of randomized, controlled trials. Neuropsychopharmacology. 2011;36:375-389.

50. Correll CU, Sheridan EM, DelBello MP. Antipsychotic and mood stabilizer efficacy and tolerability in pediatric and adult patients with bipolar I mania: a comparative analysis of acute, randomized, placebocontrolled trials. Bipolar Disord. 2010;12:116-141.

51. Tamayo JM, Zarate CA, Vieta E, Vázquez G, Tohen M. Level of response and safety of pharmacological monotherapy in the treatment of acute bipolar I disorder phases: a systematic review and meta-analysis. Int $J$ Neuropsychopharmacol. 2010;13:813-832.

52. Smith LA, Cornelius V, Warnock A, Tacchi MJ, Taylor D. Pharmacological interventions for acute bipolar mania: a systematic review of randomized placebo-controlled trials. Bipolar Disord. 2007;9:551-560.

53. Scherk H, Pajonk FG, Leucht S. Second-generation antipsychotic agents in the treatment of acute mania: a systematic review and metaanalysis of randomized controlled trials. Arch Gen Psychiatry. 2007;64: 442-455.

54. Smith LA, Cornelius V, Warnock A, Tacchi MJ, Taylor D. Acute bipolar mania: a systematic review and meta-analysis of co-therapy vs monotherapy. Acta Psychiatr Scand. 2007;115:12-20.

55. Perlis RH, Welge JA, Vornik LA, Hirschfeld RM, Keck PE Jr. Atypical antipsychotics in the treatment of mania: a meta-analysis of randomized, placebo-controlled trials. J Clin Psychiatry. 2006;67: 509-516.

56. Viguera AC, Tondo L, Baldessarini RJ. Sex differences in response to lithium treatment. Am J Psychiatry. 2000;157:1509-1511.

57. Tondo L, Baldessarini RJ, Floris G, Rudas N. Effectiveness of restarting lithium treatment after its discontinuation in bipolar I and bipolar II disorders. Am J Psychiatry. 1997;154:548-550.

58. Baldessarini RJ, Hennen J, Wilson M, et al. Olanzapine versus placebo in acute mania: treatment responses in subgroups. $J$ Clin Psychopharmacol. 2003;23:370-376.

59. Cipriani A, Barbui C, Salanti G, et al. Comparative efficacy and acceptability of antimanic drugs in acute mania: a multiple-treatments meta-analysis. Lancet. 2011;378:1306-1315.

60. Vieta E, Locklear J, Günther O, et al. Treatment options for bipolar depression: a systematic review of randomized, controlled trials. J Clin Psychopharmacol. 2010;30:579-590.

61. De FJ, Deschepper E, Audenaert K, et al. Second generation antipsychotics in the treatment of bipolar depression: a systematic review and meta-analysis. J Psychopharmacol. 2012;26:603-617.

62. Silva MT, Zimmermann IR, Galvao TF, Pereira MG. Olanzapine plus fluoxetine for bipolar disorder: a systematic review and meta-analysis. J Affect Disord. 2013;146:310-318.

63. Geddes JR, Calabrese JR, Goodwin GM. Lamotrigine for treatment of bipolar depression: independent meta-analysis and meta-regression of individual patient data from five randomised trials. $\mathrm{Br} J$ Psychiatry. 2009;194:4-9.

64. Selle V, Schalkwijk S, Vázquez GH, Baldessarini RJ. Treatments for acute bipolar depression: meta-analyses of placebo-controlled, monotherapy trials of anticonvulsants, lithium and antipsychotics. Pharmacopsychiatry. 2014;47:43-52.

65. Loebel A, Cucchiaro J, Silva R, et al. Lurasidone as adjunctive therapy with lithium or valproate for the treatment of bipolar I depression: a randomized, double-blind, placebo-controlled study. Am J Psychiatry. 2014;171:169-177.

66. Loebel A, Cucchiaro J, Silva R, et al. Lurasidone monotherapy in the treatment of bipolar I depression: a randomized, double-blind, placebocontrolled study. Am J Psychiatry. 2014;171:160-168.

67. van der Loos ML, Mulder PG, Hartong EG, et al. Efficacy and safety of lamotrigine as add-on treatment to lithium in bipolar depression: a multicenter, double-blind, placebo-controlled trial. J Clin Psychiatry. 2009;70:223-231. 
68. Young AH, McElroy SL, Bauer M, et al. A double-blind, placebocontrolled study of quetiapine and lithium monotherapy in adults in the acute phase of bipolar depression (EMBOLDEN I). J Clin Psychiatry. 2010;71:150-162.

69. Zornberg GL, Pope HG Jr. Treatment of depression in bipolar disorder: new directions for research. J Clin Psychopharmacol. 1993;13: 397-408.

70. Bond DJ, Lam RW, Yatham LN. Divalproex sodium versus placebo in the treatment of acute bipolar depression: a systematic review and meta-analysis. J Affect Disord. 2010;124:228-234.

71. Viguera AC, Nonacs R, Cohen LS, Tondo L, Murray A, Baldessarini RJ. Risk of recurrence of bipolar disorder in pregnant and nonpregnant women after discontinuing lithium maintenance. Am J Psychiatry. 2000;157:179-184.

72. Viguera AC, Whitfield T, Baldessarini RJ, et al. Risk of recurrence in women with bipolar disorder during pregnancy: prospective study of mood stabilizer discontinuation. Am J Psychiatry. 2007;164: 1817-1824.

73. Newport DJ, Stowe ZN, Viguera AC, et al. Lamotrigine in bipolar disorder: efficacy during pregnancy. Bipolar Disord. 2008;10:432-436.

74. Bergink V, Bouvy PF, Vervoort JS, Koorengevel KM, Steegers EA, Kushner SA. Prevention of postpartum psychosis and mania in women at high risk. Am J Psychiatry. 2012;169:609-615.

75. Cohen LS, Sichel DA, Robertson LM, Heckscher E, Rosenbaum JF. Postpartum prophylaxis for women with bipolar disorder. Am J Psychiatry. 1995;152:1641-1645.

76. Wisner KL, Hanusa BH, Peindl KS, Perel JM. Prevention of postpartum episodes in women with bipolar disorder. Biol Psychiatry. 2004;56: 592-596.

77. Yatham LN, Kennedy SH, Parikh SV, et al. Canadian Network for Mood and Anxiety Treatments (CANMAT) and International Society for Bipolar Disorders (ISBD) collaborative update of CANMAT guidelines for the management of patients with bipolar disorder: update 2013. Bipolar Disord. 2013;15:1-44.

78. Sachs GS. Psychosocial interventions as adjunctive therapy for bipolar disorder. J Psychiatr Pract. 2008;14 Suppl 2:39-44.

79. Szentagotai A, David D. The efficacy of cognitive-behavioral therapy in bipolar disorder: a quantitative meta-analysis. J Clin Psychiatry. 2010;71:66-72.

80. Hollon SD, Ponniah K. A review of empirically supported psychological therapies for mood disorders in adults. Depress Anxiety. 2010;27: 891-932.

81. Beynon S, Soares-Weiser K, Woolacott N, Duffy S, Geddes JR. Psychosocial interventions for the prevention of relapse in bipolar disorder: systematic review of controlled trials. Br J Psychiatry. 2008;192:5-11.

82. Miklowitz DJ. Adjunctive psychotherapy for bipolar disorder: state of the evidence. Am J Psychiatry. 2008;165:1408-1419.

83. Miklowitz DJ, Johnson SL. Social and familial factors in bipolar disorder: basic processes and relevant interventions. Clin Psychol (New York). 2009;16:281-296.

84. Harvey AG. Sleep and circadian rhythms in bipolar disorder: seeking synchrony, harmony, and regulation. Am J Psychiatry. 2008;165: 820-829.

85. Sienaert P, Lambrichts L, Dols A, De FJ. Evidence-based treatment strategies for treatment-resistant bipolar depression: a systematic review. Bipolar Disord. 2013;15:61-69.

86. UK ECT Review Group. Efficacy and safety of electroconvulsive therapy in depressive disorders: a systematic review and meta-analysis. Lancet. 2003;361:799-808.

87. Loo C, Katalinic N, Mitchell PB, Greenberg B. Physical treatments for bipolar disorder: a review of electroconvulsive therapy, stereotactic surgery and other brain stimulation techniques. J Affect Disord. 2011;132:1-13.

88. Dierckx B, Heijnen WT, van den Broek WW, Birkenhager TK. Efficacy of electroconvulsive therapy in bipolar versus unipolar major depression: a meta-analysis. Bipolar Disord. 2012;14:146-150.

89. Leiknes KA, Cooke MJ, Jarosch-von SL, Harboe I, Høie B. Electroconvulsive therapy during pregnancy: a systematic review of case studies. Arch Womens Ment Health. Epub November 24, 2013.
90. Goodwin GM. Evidence-based guidelines for treating bipolar disorder: revised second edition - recommendations from the British Association for Psychopharmacology. J Psychopharmacol. 2009;23:346-388.

91. Schou M. Lithium treatment during pregnancy, delivery, and lactation: an update. J Clin Psychiatry. 1990;51:410-413.

92. Nora JJ, Nora AH, Toews WH. Letter: Lithium, Ebstein's anomaly, and other congenital heart defects. Lancet. 1974;2:594-595.

93. Weinstein MR, Goldfield M. Cardiovascular malformations with lithium use during pregnancy. Am J Psychiatry. 1975;132:529-531.

94. Attenhofer Jost CH, Connolly HM, Dearani JA, Edwards WD, Danielson GK. Ebstein's anomaly. Circulation. 2007;115:277-285.

95. Jacobson SJ, Jones K, Johnson K, et al. Prospective multicentre study of pregnancy outcome after lithium exposure during first trimester. Lancet. 1992;339:530-533.

96. Schou M. Treating recurrent affective disorders during and after pregnancy. What can be taken safely? Drug Saf. 1998;18:143-152.

97. Kallen B, Tandberg A. Lithium and pregnancy. A cohort study on manic-depressive women. Acta Psychiatr Scand. 1983;68:134-139.

98. Cohen LS, Friedman JM, Jefferson JW, Johnson EM, Weiner ML. A reevaluation of risk of in utero exposure to lithium. JAMA. 1994;271: 146-150.

99. Lupo PJ, Langlois PH, Mitchell LE. Epidemiology of Ebstein anomaly: prevalence and patterns in Texas, 1999-2005. Am J Med Genet A. 2011;155A:1007-1014.

100. Yacobi S, Ornoy A. Is lithium a real teratogen? What can we conclude from the prospective versus retrospective studies? A review. Isr $J$ Psychiatry Relat Sci. 2008;45:95-106.

101. Llewellyn A, Stowe ZN, Strader JR Jr. The use of lithium and management of women with bipolar disorder during pregnancy and lactation. J Clin Psychiatry. 1998;59 Suppl 6:57-64.

102. Simard M, Gumbiner B, Lee A, Lewis H, Norman D. Lithium carbonate intoxication. A case report and review of the literature. Arch Intern Med. 1989;149:36-46.

103. Kozma C. Neonatal toxicity and transient neurodevelopmental deficits following prenatal exposure to lithium: another clinical report and a review of the literature. Am J Med Genet A. 2005;132:441-444.

104. Newport DJ, Viguera AC, Beach AJ, Ritchie JC, Cohen LS, Stowe ZN. Lithium placental passage and obstetrical outcome: implications for clinical management during late pregnancy. Am J Psychiatry. 2005;162:2162-2170.

105. Karlsson K, Lindstedt G, Lundberg PA, Selstam U. Letter: Transplacental lithium poisoning: reversible inhibition of fetal thyroid. Lancet. 1975;1:1295.

106. Mizrahi EM, Hobbs JF, Goldsmith DI. Nephrogenic diabetes insipidus in transplacental lithium intoxication. J Pediatr. 1979;94:493-495.

107. Schou M. What happened later to the lithium babies? A follow-up study of children born without malformations. Acta Psychiatr Scand. 1976;54:193-197.

108. Troyer WA, Pereira GR, Lannon RA, Belik J, Yoder MC. Association of maternal lithium exposure and premature delivery. J Perinatol. 1993;13:123-127.

109. Galbally M, Roberts M, Buist A. Mood stabilizers in pregnancy: a systematic review. Aust N Z J Psychiatry. 2010;44:967-977.

110. Bjerkedal T, Czeizel A, Goujard J, et al. Valproic acid and spina bifida. Lancet. 1982;2:1096.

111. Jäger-Roman E, Deichl A, Jakob S, et al. Fetal growth, major malformations, and minor anomalies in infants born to women receiving valproic acid. J Pediatr. 1986;108:997-1004.

112. Lindhout D, Schmidt D. In-utero exposure to valproate and neural tube defects. Lancet. 1986;1:1392-1393.

113. Samrén EB, van Duijn CM, Koch S, et al. Maternal use of antiepileptic drugs and the risk of major congenital malformations: a joint European prospective study of human teratogenesis associated with maternal epilepsy. Epilepsia. 1997;38:981-990.

114. Mawer G, Briggs M, Baker GA, et al. Pregnancy with epilepsy: obstetric and neonatal outcome of a controlled study. Seizure. 2010;19: 112-119. 
115. WyszynskiDF,Nambisan M, Surve T,AlsdorfRM, Smith CR, Holmes LB. Increased rate of major malformations in offspring exposed to valproate during pregnancy. Neurology. 2005;64:961-965.

116. Artama M, Auvinen A, Raudaskoski T, Isojärvi I, Isojärvi J. Antiepileptic drug use of women with epilepsy and congenital malformations in offspring. Neurology. 2005;64:1874-1878.

117. Morrow J, Russell A, Guthrie E, et al. Malformation risks of antiepileptic drugs in pregnancy: a prospective study from the UK Epilepsy and Pregnancy Register. J Neurol Neurosurg Psychiatry. 2006;77: 193-198.

118. Hernández-Díaz S, Smith CR, Shen A, et al. Comparative safety of antiepileptic drugs during pregnancy. Neurology. 2012;78:1692-1699.

119. Tomson T, Battino D, Bonizzoni E, et al. Dose-dependent risk of malformations with antiepileptic drugs: an analysis of data from the EURAP epilepsy and pregnancy registry. Lancet Neurol. 2011;10:609-617.

120. Tomson T, Battino D. Teratogenic effects of antiepileptic drugs. Lancet Neurol. 2012;11:803-813.

121. Wide K, Winbladh B, Kallen B. Major malformations in infants exposed to antiepileptic drugs in utero, with emphasis on carbamazepine and valproic acid: a nation-wide, population-based register study. Acta Paediatr. 2004;93:174-176.

122. Vajda FJ, O'Brien TJ, Hitchcock A, Graham J, Lander C. The Australian registry of anti-epileptic drugs in pregnancy: experience after 30 months. J Clin Neurosci. 2003;10:543-549.

123. Vajda FJ, Graham J, Roten A, Lander CM, O’Brien TJ, Eadie M. Teratogenicity of the newer antiepileptic drugs - the Australian experience. J Clin Neurosci. 2012;19:57-59.

124. Kaaja E, Kaaja R, Hiilesmaa V. Major malformations in offspring of women with epilepsy. Neurology. 2003;60:575-579.

125. Diav-Citrin O, Shechtman S, Bar-Oz B, Cantrell D, Arnon J, Ornoy A. Pregnancy outcome after in utero exposure to valproate: evidence of dose relationship in teratogenic effect. CNS Drugs. 2008;22: 325-334.

126. Omtzigt JG, Los FJ, Grobbee DE, et al. The risk of spina bifida aperta after first-trimester exposure to valproate in a prenatal cohort. Neurology. 1992;42:119-125.

127. Lajeunie E, Barcik U, Thorne JA, El Ghouzzi V, Bourgeois M, Renier D. Craniosynostosis and fetal exposure to sodium valproate. J Neurosurg. 2001;95:778-782.

128. Paulson GW, Paulson RB. Teratogenic effects of anticonvulsants. Arch Neurol. 1981;38:140-143.

129. Rodríguez-Pinilla E, Arroyo I, Fondevilla J, García MJ, MartínezFrías ML. Prenatal exposure to valproic acid during pregnancy and limb deficiencies: a case-control study. Am J Med Genet. 2000;90: 376-381.

130. DiLiberti JH, Farndon PA, Dennis NR, Curry CJ. The fetal valproate syndrome. Am J Med Genet. 1984;19:473-481.

131. Moore SJ, Turnpenny P, Quinn A, et al. A clinical study of 57 children with fetal anticonvulsant syndromes. J Med Genet. 2000;37:489-497.

132. Jentink J, Loane MA, Dolk H, et al. Valproic acid monotherapy in pregnancy and major congenital malformations. $N$ Engl $J$ Med. 2010;362:2185-2193.

133. Holmes LB, Mittendorf R, Shen A, Smith CR, Hernandez-Diaz S. Fetal effects of anticonvulsant polytherapies: different risks from different drug combinations. Arch Neurol. 2011;68:1275-1281.

134. Kaneko S, Battino D, Andermann E, et al. Congenital malformations due to antiepileptic drugs. Epilepsy Res. 1999;33:145-158.

135. Vajda FJ, Hitchcock AA, Graham J, O'Brien TJ, Lander CM, Eadie MJ. The teratogenic risk of antiepileptic drug polytherapy. Epilepsia. 2010;51:805-810.

136. Kennedy D, Koren G. Valproic acid use in psychiatry: issues in treating women of reproductive age. J Psychiatry Neurosci. 1998;23: 223-228.

137. Mountain KR, Hirsh J, Gallus AS. Neonatal coagulation defect due to anticonvulsant drug treatment in pregnancy. Lancet. 1970;1: 265-268.

138. Ebbesen F, Joergensen A, Hoseth E, et al. Neonatal hypoglycaemia and withdrawal symptoms after exposure in utero to valproate. Arch Dis Child Fetal Neonatal Ed. 2000;83:F124-F129.
139. Thisted E, Ebbesen F. Malformations, withdrawal manifestations, and hypoglycaemia after exposure to valproate in utero. Arch Dis Child. 1993;69:288-291.

140. Pennell PB, Klein AM, Browning N, et al. Differential effects of antiepileptic drugs on neonatal outcomes. Epilepsy Behav. 2012;24: 449-456.

141. Meador KJ, Baker GA, Browning N, et al. Fetal antiepileptic drug exposure and cognitive outcomes at age 6 years (NEAD study): a prospective observational study. Lancet Neurol. 2013;12:244-252.

142. Gaily E, Kantola-Sorsa E, Hiilesmaa V, et al. Normal intelligence in children with prenatal exposure to carbamazepine. Neurology. 2004;62:28-32.

143. Vinten J, Adab N, Kini U, Gorry J, Gregg J, Baker GA. Neuropsychological effects of exposure to anticonvulsant medication in utero. Neurology. 2005;64:949-954.

144. Adab N, Kini U, Vinten J, et al. The longer term outcome of children born to mothers with epilepsy. J Neurol Neurosurg Psychiatry. 2004; 75:1575-1583.

145. Shallcross R, Bromley RL, Cheyne CP, et al. In utero exposure to levetiracetam vs valproate: development and language at 3 years of age. Neurology. 2014;82:213-221.

146. Veiby G, Daltveit AK, Schjølberg S, et al. Exposure to antiepileptic drugs in utero and child development: a prospective population-based study. Epilepsia. 2013;54:1462-1472.

147. Meador KJ, Baker GA, Browning N, et al. Foetal antiepileptic drug exposure and verbal versus non-verbal abilities at three years of age. Brain. 2011;134:396-404.

148. Cohen MJ, Meador KJ, Browning N, et al. Fetal antiepileptic drug exposure: adaptive and emotional/behavioral functioning at age 6 years. Epilepsy Behav. 2013;29:308-315.

149. Adab N, Jacoby A, Smith D, Chadwick D. Additional educational needs in children born to mothers with epilepsy. J Neurol Neurosurg Psychiatry. 2001;70:15-21.

150. Rasalam AD, Hailey H, Williams JH, et al. Characteristics of fetal anticonvulsant syndrome associated autistic disorder. Dev Med Child Neurol. 2005;47:551-555.

151. Bromley RL, Mawer G, Clayton-Smith J, Baker GA. Autism spectrum disorders following in utero exposure to antiepileptic drugs. Neurology. 2008;71:1923-1924.

152. Bromley RL, Mawer GE, Briggs M, et al. The prevalence of neurodevelopmental disorders in children prenatally exposed to antiepileptic drugs. J Neurol Neurosurg Psychiatry. 2013;84:637-643.

153. Bescoby-Chambers N, Forster P, Bates G. 'Foetal valproate syndrome and autism: additional evidence of an association' [comment]. Dev Med Child Neurol. 2001;43:847.

154. Williams G, King J, Cunningham M, Stephan M, Kerr B, Hersh JH. Fetal valproate syndrome and autism: additional evidence of an association. Dev Med Child Neurol. 2001;43:202-206.

155. Jentink J, Dolk H, Loane MA, et al. Intrauterine exposure to carbamazepine and specific congenital malformations: systematic review and case-control study. BMJ. 2010;341:c6581.

156. Matalon S, Schechtman S, Goldzweig G, Ornoy A. The teratogenic effect of carbamazepine: a meta-analysis of 1255 exposures. Reprod Toxicol. 2002;16:9-17.

157. Tomson T, Battino D. Teratogenic effects of antiepileptic medications. Neurol Clin. 2009;27:993-1002.

158. Samrén EB, van Duijn CM, Christiaens GC, Hofman A, Lindhout D. Antiepileptic drug regimens and major congenital abnormalities in the offspring. Ann Neurol. 1999;46:739-746.

159. Hernández-Díaz S, Werler MM, Walker AM, Mitchell AA. Neural tube defects in relation to use of folic acid antagonists during pregnancy. Am J Epidemiol. 2001;153:961-968.

160. Jones KL, Lacro RV, Johnson KA, Adams J. Pattern of malformations in the children of women treated with carbamazepine during pregnancy. N Engl J Med. 1989;320:1661-1666.

161. Ornoy A, Cohen E. Outcome of children born to epileptic mothers treated with carbamazepine during pregnancy. Arch Dis Child. $1996 ; 75: 517-520$ 
162. Wide K, Winbladh B, Tomson T, Sars-Zimmer K, Berggren E. Psychomotor development and minor anomalies in children exposed to antiepileptic drugs in utero: a prospective population-based study. Dev Med Child Neurol. 2000;42:87-92.

163. Nulman I, Scolnik D, Chitayat D, Farkas LD, Koren G. Findings in children exposed in utero to phenytoin and carbamazepine monotherapy: independent effects of epilepsy and medications. Am J Med Genet. 1997;68:18-24.

164. Diav-Citrin O, Shechtman S, Arnon J, Ornoy A. Is carbamazepine teratogenic? A prospective controlled study of 210 pregnancies. Neurology. 2001;57:321-324.

165. Iqbal MM, Gundlapalli SP, Ryan WG, Ryals T, Passman TE. Effects of antimanic mood-stabilizing drugs on fetuses, neonates, and nursing infants. South Med J. 2001;94:304-322.

166. Holmes LB, Coull BA, Dorfman J, Rosenberger PB. The correlation of deficits in IQ with midface and digit hypoplasia in children exposed in utero to anticonvulsant drugs. J Pediatr. 2005;146:118-122.

167. Titze K, Koch S, Helge H, Lehmkuhl U, Rauh H, Steinhausen HC. Prenatal and family risks of children born to mothers with epilepsy: effects on cognitive development. Dev Med Child Neurol. 2008;50: $117-122$.

168. Cunnington M, Tennis P. Lamotrigine and the risk of malformations in pregnancy. Neurology. 2005;64:955-960.

169. Tennis P, Eldridge RR. Preliminary results on pregnancy outcomes in women using lamotrigine. Epilepsia. 2002;43:1161-1167.

170. Cunnington MC, Weil JG, Messenheimer JA, Ferber S, Yerby M, Tennis P. Final results from 18 years of the International Lamotrigine Pregnancy Registry. Neurology. 2011;76:1817-1823.

171. Meador KJ, Baker GA, Finnell RH, et al. In utero antiepileptic drug exposure: fetal death and malformations. Neurology. 2006;67: 407-412.

172. Holmes LB, Baldwin EJ, Smith CR, et al. Increased frequency of isolated cleft palate in infants exposed to lamotrigine during pregnancy. Neurology. 2008;70:2152-2158.

173. Dolk H, Jentink J, Loane M, Morris J, de Jong-van den Berg LT. Does lamotrigine use in pregnancy increase orofacial cleft risk relative to other malformations? Neurology. 2008;71:714-722.

174. Sabers A, Dam M, A-Rogvi-Hansen B, et al. Epilepsy and pregnancy: lamotrigine as main drug used. Acta Neurol Scand. 2004;109:9-13.

175. Mølgaard-Nielsen D, Hviid A. Newer-generation antiepileptic drugs and the risk of major birth defects. JAMA. 2011;305:1996-2002.

176. Cunnington M, Ferber S, Quartey G. Effect of dose on the frequency of major birth defects following fetal exposure to lamotrigine monotherapy in an international observational study. Epilepsia. 2007;48: $1207-1210$

177. Vajda FJ, Graham JE, Hitchcock AA, O'Brien TJ, Lander CM, Eadie MJ. Is lamotrigine a significant human teratogen? Observations from the Australian Pregnancy Register. Seizure. 2010;19:558-561.

178. Gentile S. Antipsychotic therapy during early and late pregnancy. A systematic review. Schizophr Bull. 2010;36:518-544.

179. Einarson A, Boskovic R. Use and safety of antipsychotic drugs during pregnancy. J Psychiatr Pract. 2009;15:183-192.

180. Diav-Citrin O, Shechtman S, Ornoy S, et al. Safety of haloperidol and penfluridol in pregnancy: a multicenter, prospective, controlled study. J Clin Psychiatry. 2005;66:317-322.

181. Coppola D, Russo LJ, Kwarta RF Jr, Varughese R, Schmider J. Evaluating the postmarketing experience of risperidone use during pregnancy: pregnancy and neonatal outcomes. Drug Saf. 2007;30: 247-264.

182. Goldstein DJ, Corbin LA, Fung MC. Olanzapine-exposed pregnancies and lactation: early experience. J Clin Psychopharmacol. 2000;20: 399-403.

183. McKenna K, Koren G, Tetelbaum M, et al. Pregnancy outcome of women using atypical antipsychotic drugs: a prospective comparative study. J Clin Psychiatry. 2005;66:444-449.

184. Reis M, Kallen B. Maternal use of antipsychotics in early pregnancy and delivery outcome. J Clin Psychopharmacol. 2008;28: 279-288.
185. Tényi T, Trixler M, Keresztes Z. Quetiapine and pregnancy. $A m J$ Psychiatry. 2002;159:674.

186. Taylor TM, O’Toole MS, Ohlsen RI, Walters J, Pilowsky LS. Safety of quetiapine during pregnancy. Am J Psychiatry. 2003;160: 588-589.

187. Gentile S. Quetiapine-fluvoxamine combination during pregnancy and while breastfeeding. Arch Womens Ment Health. 2006;9: 158-159.

188. Yaeger D, Smith HG, Altshuler LL. Atypical antipsychotics in the treatment of schizophrenia during pregnancy and the postpartum. Am J Psychiatry. 2006;163:2064-2070.

189. Mendhekar DN, Sunder KR, Andrade C. Aripiprazole use in a pregnant schizoaffective woman. Bipolar Disord. 2006;8:299-300.

190. Kulkarni J, Cauley-Elsom K, Marston N, et al. Preliminary findings from the National Register of Antipsychotic Medication in Pregnancy. Aust N Z J Psychiatry. 2008;42:38-44.

191. U.S. Food and Drug Administration. FDA Drug Safety Communication: Antipsychotic drug labels updated on use during pregnancy and risk of abnormal muscle movements and withdrawl symptoms in newborns. Issued February 2, 2011. Available online http://www.fda. gov/Drugs/DrugSafety/ucm243903.htm. Accessed on December 1, 2014.

192. Newcomer JW. Second-generation (atypical) antipsychotics and metabolic effects: a comprehensive literature review. CNS Drugs. 2005;19 Suppl 1:1-93.

193. Newham JJ, Thomas SH, MacRitchie K, McElhatton PR, McAllisterWilliams RH. Birth weight of infants after maternal exposure to typical and atypical antipsychotics: prospective comparison study. $\mathrm{Br}$ J Psychiatry. 2008;192:333-337.

194. Babu GN, Desai G, Tippeswamy H, Chandra PS. Birth weight and use of olanzapine in pregnancy: a prospective comparative study. J Clin Psychopharmacol. 2010;30:331-332.

195. Newport DJ, Calamaras MR, DeVane CL, et al. Atypical antipsychotic administration during late pregnancy: placental passage and obstetrical outcomes. Am J Psychiatry. 2007;164:1214-1220.

196. Bodén R, Lundgren M, Brandt L, Reutfors J, Kieler H. Antipsychotics during pregnancy: relation to fetal and maternal metabolic effects. Arch Gen Psychiatry. 2012;69:715-721.

197. Johnson KC, LaPrairie JL, Brennan PA, Stowe ZN, Newport DJ. Prenatal antipsychotic exposure and neuromotor performance during infancy. Arch Gen Psychiatry. 2012;69:787-794.

198. Miller LJ. Use of electroconvulsive therapy during pregnancy. Hosp Community Psychiatry. 1994;45:444-450.

199. Anderson EL, Reti IM. ECT in pregnancy: a review of the literature from 1941 to 2007. Psychosom Med. 2009;71:235-242.

200. Rabheru K. The use of electroconvulsive therapy in special patient populations. Can J Psychiatry. 2001;46:710-719.

201. Briggs GG. Drugs in Pregnancy and Lactation: A Reference Guide to Fetal and Neonatal Risk. 9th ed. Philadelphia: Lippincott Williams \& Wilkins; 2011

202. Freeman MP, Smith KW, Freeman SA, et al. The impact of reproductive events on the course of bipolar disorder in women. J Clin Psychiatry. 2002;63:284-287.

203. Viguera AC, Cohen LJ, Tondo L, Baldessarini RJ. Protective effect of pregnancy on the course of lithium-responsive bipolar I disorder. $J$ Affect Disord. 2002;72:107-108.

204. Grof P, Robbins W, Alda M, et al. Protective effect of pregnancy in women with lithium-responsive bipolar disorder. $J$ Affect Disord. 2000;61:31-39.

205. Sharma V, Pope CJ. Pregnancy and bipolar disorder: a systematic review. J Clin Psychiatry. 2012;73:1447-1455.

206. Clark CT, Wisner KL. Response to Sharma and Sommerdyk. Am J Psychiatry. 2014;171:371.

207. Fried S, Kozer E, Nulman I, Einarson TR, Koren G. Malformation rates in children of women with untreated epilepsy: a meta-analysis. Drug Saf. 2004;27:197-202.

208. Nguyen HT, Sharma V, McIntyre RS. Teratogenesis associated with antibipolar agents. Adv Ther. 2009;26:281-294. 
209. Bromfield EB, Dworetzky BA, Wyszynski DF, Smith CR, Baldwin EJ, Holmes LB. Valproate teratogenicity and epilepsy syndrome. Epilepsia. 2008;49:2122-2124.

210. Morrow JI, Hunt SJ, Russell AJ, et al. Folic acid use and major congenital malformations in offspring of women with epilepsy: a prospective study from the UK Epilepsy and Pregnancy Register. J Neurol Neurosurg Psychiatry. 2009;80:506-511.

211. Jentink J, Bakker MK, Nijenhuis CM, Wilffert B, de Jong-van den Berg LT. Does folic acid use decrease the risk for spina bifida after in utero exposure to valproic acid? Pharmacoepidemiol Drug Saf. 2010;19:803-807.

212. Centers for Disease Control and Prevention. Folic acid. 2014. Available from: http://www.cdc.gov/ncbddd/folicacid/index.html. Accessed October 27, 2014.

213. Yerby MS. Management issues for women with epilepsy: neural tube defects and folic acid supplementation. Neurology. 2003;61: S23-S26.

214. Cohen LS, Wang B, Nonacs R, Viguera AC, Lemon EL, Freeman MP. Treatment of mood disorders during pregnancy and postpartum. Psychiatr Clin North Am. 2010;33:273-293.

215. Vieta E, Langosch JM, Figueira ML, et al. Clinical management and burden of bipolar disorder: results from a multinational longitudinal study (WAVE-bd). Int J Neuropsychopharmacol. 2013;16: 1719-1732.

216. Pillarella J, Higashi A, Alexander GC, Conti R. Trends in use of second-generation antipsychotics for treatment of bipolar disorder in the United States, 1998-2009. Psychiatr Serv. 2012;63: $83-86$.

217. Depp C, Ojeda VD, Mastin W, Unutzer J, Gilmer TP. Trends in use of antipsychotics and mood stabilizers among Medicaid beneficiaries with bipolar disorder, 2001-2004. Psychiatr Serv. 2008;59:1169-1174.

218. Bobo WV, Cooper WO, Stein CM, et al. Antipsychotics and the risk of type 2 diabetes mellitus in children and youth. JAMA Psychiatry. 2013;70:1067-1075

219. Lambert BL, Cunningham FE, Miller DR, Dalack GW, Hur K. Diabetes risk associated with use of olanzapine, quetiapine, and risperidone in Veterans Health Administration patients with schizophrenia. Am J Epidemiol. 2006;164:672-681.

220. Hendricks KA, Nuno OM, Suarez L, Larsen R. Effects of hyperinsulinemia and obesity on risk of neural tube defects among Mexican Americans. Epidemiology. 2001;12:630-635.

221. Shaw GM, Todoroff K, Finnell RH, Lammer EJ. Spina bifida phenotypes in infants or fetuses of obese mothers. Teratology. 2000;61: 376-381.

222. Watkins ML, Rasmussen SA, Honein MA, Botto LD, Moore CA. Maternal obesity and risk for birth defects. Pediatrics. 2003;111: $1152-1158$.

223. Ray JG, Wyatt PR, Vermeulen MJ, Meier C, Cole DE. Greater maternal weight and the ongoing risk of neural tube defects after folic acid flour fortification. Obstet Gynecol. 2005;105:261-265.

224. Mikhail LN, Walker CK, Mittendorf R. Association between maternal obesity and fetal cardiac malformations in African Americans. J Natl Med Assoc. 2002;94:695-700.

225. Cedergren MI, Källén BA. Maternal obesity and infant heart defects. Obes Res. 2003;11:1065-1071.

226. Judd LL, Akiskal HS, Schettler PJ, et al. A prospective investigation of the natural history of the long-term weekly symptomatic status of bipolar II disorder. Arch Gen Psychiatry. 2003;60:261-269.

227. Goldberg JF, Garno JL, Harrow M. Long-term remission and recovery in bipolar disorder: a review. Curr Psychiatry Rep. 2005;7: 456-461.

228. Craig TJ, Grossman S, Mojtabai R, et al. Medication use patterns and 2-year outcome in first-admission bipolar disorder with psychotic features. Bipolar Disord. 2004;6:406-415.

229. Baldessarini R, Henk H, Sklar A, Chang J, Leahy L. Psychotropic medications for patients with bipolar disorder in the United States: polytherapy and adherence. Psychiatr Serv. 2008;59:1175-1183.
230. Antenatal and Postnatal Mental Health: National Institute for Health and Care Excellence. The NICE Guideline on Clinical Management and Service Guidance. NICE; 2007.

231. Wisner KL. The last therapeutic orphan: the pregnant woman. Am J Psychiatry. 2012;169:554-556.

232. Abel KM. Fetal antipsychotic exposure in a changing landscape: seeing the future. Br J Psychiatry. 2013;202:321-323.

233. ACOG Committee on Practice Bulletins - Obstetrics. ACOG Practice Bulletin: Clinical management guidelines for obstetrician-gynecologists number 92, April 2008 (replaces practice bulletin number 87, November 2007). Use of psychiatric medications during pregnancy and lactation. Obstet Gynecol. 2008;111:1001-1020.

234. Yonkers KA, Wisner KL, Stowe Z, et al. Management of bipolar disorder during pregnancy and the postpartum period. Am J Psychiatry. 2004;161:608-620.

235. Malhi GS, Adams D, Lampe L, et al. Clinical practice recommendations for bipolar disorder. Acta Psychiatr Scand Suppl. 2009:27-46.

236. Llorca PM, Courtet P, Martin P, et al. [Screening and management of bipolar disorders: results]. Encephale. 2010;36 Suppl 4:S86-S102. French.

237. Samalin L, Guillaume S, Courtet P, Abbar M, Lancrenon S, Llorca PM. Methodological differences between pharmacological treatment guidelines for bipolar disorder: what to do for the clinicians? Compr Psychiatry. 2013;54:309-320.

238. Heffner JL, DelBello MP, Fleck DE, Adler CM, Strakowski SM. Unplanned pregnancies in adolescents with bipolar disorder. $\mathrm{Am} J$ Psychiatry. 2012;169:1319.

239. Freeman MP. Bipolar disorder and pregnancy: risks revealed. Am J Psychiatry. 2007;164:1771-1773.

240. Nivoli AM, Murru A, Goikolea JM, et al. New treatment guidelines for acute bipolar mania: a critical review. J Affect Disord. 2012;140: 125-141.

241. Altshuler LL, Cohen L, Szuba MP, Burt VK, Gitlin M, Mintz J. Pharmacologic management of psychiatric illness during pregnancy: dilemmas and guidelines. Am J Psychiatry. 1996;153:592-606.

242. Cohen LS. Treatment of bipolar disorder during pregnancy. J Clin Psychiatry. 2007;68 Suppl 9:4-9.

243. Burt VK, Bernstein C, Rosenstein WS, Altshuler LL. Bipolar disorder and pregnancy: maintaining psychiatric stability in the real world of obstetric and psychiatric complications. Am J Psychiatry. 2010;167: 892-897.

244. Yerby MS, Friel PN, McCormick K. Antiepileptic drug disposition during pregnancy. Neurology. 1992;42:12-16.

245. Sabers A, Tomson T. Managing antiepileptic drugs during pregnancy and lactation. Curr Opin Neurol. 2009;22:157-161.

246. Clark CT, Klein AM, Perel JM, Helsel J, Wisner KL. Lamotrigine dosing for pregnant patients with bipolar disorder. Am J Psychiatry. 2013;170:1240-1247.

247. Zhang Y, Yang H, Yang S, et al. Antidepressants for bipolar disorder: a meta-analysis of randomized, double-blind, controlled trials. Neural Regen Res. 2013;8:2962-2974.

248. Sharma V. Considerations in the pharmacotherapy of bipolar disorder during and after pregnancy. Curr Drug Saf. 2011;6:318-323.

249. Altshuler L, Suppes T, Black D, et al. Impact of antidepressant discontinuation after acute bipolar depression remission on rates of depressive relapse at 1-year follow-up. Am J Psychiatry. 2003;160:1252-1262.

250. Post RM, Leverich GS, Nolen WA, et al. A re-evaluation of the role of antidepressants in the treatment of bipolar depression: data from the Stanley Foundation Bipolar Network. Bipolar Disord. 2003;5: 396-406.

251. Gitlin M. Treatment-resistant bipolar disorder. Mol Psychiatry. 2006;11:227-240.

252. Wang PW, Ketter TA. Pharmacokinetics of mood stabilizers and new anticonvulsants. Psychopharmacol Bull. 2002;36:44-66.

253. Kazmin A, Wong RC, Sermer M, Koren G. Antiepileptic drugs in pregnancy and hemorrhagic disease of the newborn. Can Fam Physician. 2010;56:1291-1292. 
254. Harden CL, Pennell PB, Koppel BS, et al. Management issues for women with epilepsy - focus on pregnancy (an evidence-based review): III. Vitamin K, folic acid, blood levels, and breast-feeding: Report of the Quality Standards Subcommittee and Therapeutics and Technology Assessment Subcommittee of the American Academy of Neurology and the American Epilepsy Society. Epilepsia. 2009;50: 1247-1255.

255. Stowe $\mathrm{ZN}$. The use of mood stabilizers during breastfeeding. J Clin Psychiatry. 2007;68 Suppl 9:22-28.

256. Viguera AC, Newport DJ, Ritchie J, et al. Lithium in breast milk and nursing infants: clinical implications. Am J Psychiatry. 2007;164: 342-345.

257. Bond DJ, Pratoomsri W, Yatham LN. Depot antipsychotic medications in bipolar disorder: a review of the literature. Acta Psychiatr Scand Suppl. 2007:43:3-16.
258. Surja AA, Tamas RL, El-Mallakh RS. Antipsychotic medications in the treatment of bipolar disorder. Curr Drug Targets. 2006;7: 1217-1224.

259. Margolese HC, Chouinard G, Kolivakis TT, Beauclair L, Miller R, Annable L. Tardive dyskinesia in the era of typical and atypical antipsychotics. Part 2: Incidence and management strategies in patients with schizophrenia. Can J Psychiatry. 2005;50:703-714.

260. Cooper WO, Hernandez-Diaz S, Gideon P, et al. Positive predictive value of computerized records for major congenital malformations. Pharmacoepidemiol Drug Saf. 2008;17:455-460.

261. Bobo WV, Davis RL, Toh S, et al. Trends in the use of antiepileptic drugs among pregnant women in the US, 2001-2007: a medication exposure in pregnancy risk evaluation program study. Paediatr Perinat Epidemiol. 2012;26:578-588.

\section{Publish your work in this journal}

Drug, Healthcare and Patient Safety is an international, peer-reviewed open-access journal exploring patient safety issues in the healthcare continuum from diagnostic and screening interventions through to treatment, drug therapy and surgery. The journal is characterized by the rapic reporting of reviews, original research, clinical, epidemiological and

\section{Dovepress}

post-marketing surveillance studies, risk management, health literacy and educational programs across all areas of healthcare delivery. The manuscript management system is completely online and includes a very quick and fair peer-review system. Visit http://www.dovepress.com/ testimonials.php to read real quotes from published authors.

Submit your manuscript here: http://www.dovepress.com/drug-healthcare-and-patient-safety-journal 